\title{
Assessment of solar radiation models and temporal averaging schemes in predicting radiation and cotton production in the southern United States
}

\author{
A. G. Richardson, K. Raja Reddy* \\ Department of Plant and Soil Sciences, Box 955, 117 Dorman Hall, Mississippi State University, Mississippi State, \\ Mississippi 39762, USA
}

\begin{abstract}
Crop models require daily weather input data for solar radiation $\left(I_{\mathrm{rad}}\right)$, minimum and maximum air temperatures, precipitation, and windspeed; but measured $I_{\text {rad }}$ may not be available at some locations, necessitating $I_{\text {rad }}$ estimates. A total of 28 scenarios $(7$ solar radiation models [SRMs] $\times$ 4 temporal-averaging schemes [TASs]) were examined to estimate $I_{\text {rad }}$ and cotton (Gossypium hirsutum L.) yield at 10 U.S. locations. The SRMs showed positive correlations of $I_{\text {rad }}$ with daylength and temperature range $\left(T_{\max }-T_{\min }\right)$, and were relatively accurate in predicting $I_{\text {rad }}$ and yield. The $I_{\text {rad }}$ estimation accuracy depended on SRM, TAS, and location. Temporal averaging smoothed out short-term fluctuations, resulting in decreased temporal scatter in the weather parameters. The combination of $T_{\min }, T_{\max }$, precipitation and wind (TmRnWn) model performed best, and $I_{\text {rad }}$ estimation accuracy was highest in Shafter, California, and Maricopa, Arizona. Highest $I_{\text {rad }}$ estimation accuracy was obtained with the TmRnWn model, using a double TAS, in Maricopa $\left(\mathrm{r}^{2}=0.99\right)$. Geographical variability in $I_{\text {rad }}$ was observed, showing effects of regional climate on measured $I_{\text {rad }}$ and on $I_{\text {rad }}$ estimation accuracy. Yield estimation accuracy depended on $I_{\text {rad }}$ estimation accuracy and yield response to $I_{\text {rad }}$ changes, and depended more strongly on location and management practice (rainfed [RF] versus irrigated [IRR]) than on SRM and TAS. All 7 SRMs performed comparably well in predicting RF and IRR yields. Estimation accuracies for $I_{\text {rad }}$ and RF + IRR cotton yields among the 28 scenarios were highest for Shafter and Maricopa (e.g. $\mathrm{r}^{2}>0.99$ for yield). Coupled with crop simulation models, SRMs are useful for predicting $I_{\text {rad }}$ and crop yields, particularly in regions with unavailable measured $I_{\text {rad }}$ data.
\end{abstract}

KEY WORDS: Temporal-averaging scheme $\cdot$ TAS $\cdot$ Solar radiation model $\cdot$ SRM $\cdot$ Crop simulation model $\cdot$ CSM $\cdot$ GOSSYM $\cdot$ Cotton

\section{INTRODUCTION}

Numerous solar radiation models (SRMs) have been developed, calibrated, and evaluated to estimate solar radiation incident on the earth's surface $\left(R_{\mathrm{g}}, \mathrm{MJ} \mathrm{m} \mathrm{m}^{-2}\right.$ $\mathrm{d}^{-1}$ ) as a function of extraterrestrial (Angot) solar radiation at the top of the atmosphere $\left(R_{\mathrm{a}}, \mathrm{MJ} \mathrm{m}^{-2} \mathrm{~d}^{-1}\right)$ and atmospheric conditions (Angstrom 1924, Davies 1965, Bristow \& Campbell 1984, Martinez-Lozano et al. 1984, Allen 1995, 1997, Meza \& Varas 2000). The $R_{\text {a }}$ parameter is a general function of the solar constant $(1370 \mathrm{~W}$ $\mathrm{m}^{-2}$ ), the ratio of the annual mean to the actual earth- sun distance, latitude, solar elevation angle, and solar declination angle (Meza \& Varas 2000).

Empirical algorithms have been proposed relating $R_{\mathrm{g}}$ or the $R_{\mathrm{g}} / R_{\mathrm{a}}$ ratio to weather parameters (Meza \& Varas 2000), most commonly the daily or monthly mean maximum $\left(T_{\max }\right)$ and minimum $\left(T_{\min }\right)$ air temperatures and temperature range $\left(T_{\max }-T_{\min }\right)$ (Liu \& Jordan 1963, Reddy 1971, Goldberg et al. 1979, Bristow \& Campbell 1984, Hargreaves et al. 1985, Richardson 1985, Allen 1995, 1997, Goodin et al. 1999), as well as other parameters such as daylength (Angstrom 1924, Martinez-Lozano et al. 1984), precipitation (McCaskill 
1990a,b), and both temperature and precipitation (DeJong \& Stewart 1993, Hunt et al. 1998, Liu \& Scott 2001). Once calibrated, evaluated, and incorporated into SRMs, these algorithms are useful particularly in regions lacking measured solar radiation data (Hooke \& McClendon 1992).

To potentially improve solar raadition prediction, a new SRM model, TmRnWn model, is introduced and compared with the above SRMs. Two additional weather parameters (along with $T_{\max }$ and $T_{\min }$ ) are incorporated into the new model: precipitation (PPT) and windspeed (WIND). The 'TmRnWn' notation refers to ' $\mathrm{Tm}$ ' = temperature, ' $\mathrm{Rn}$ ' = rain (precipitation), and ' $\mathrm{Wn}$ ' = windspeed. Justification for including these parameters is that solar radiation is correlated with PPT and WIND, as well as with air temperature. High PPT is associated with frequent cloud cover and hence lower solar radiation; and high WIND is associated with strong air pressure gradients, fronts, and storm systems, which in turn are associated with lower solar radiation. Thus, solar radiation typically correlates negatively with both PPT and WIND.

In addition to predicting solar radiation, SRMs are also useful when coupled with crop simulation models (CSMs) to predict crop production. Variability in climate and weather parameters, including solar radiation, governs crop production variability. Crop response to environmental (climate) change is an important global issue among agriculturists, climatologists, economists, and policy makers. Several CSMs have been developed to simulate crop performance and response to changes in weather/climate, management, soil properties, and crop cultivar properties. Climate change sensitivity studies have been conducted to assess crop response under various projected future climate scenarios (IPCC 2001). Assessment accuracy is governed by accuracies of future climate projection, CSM parameterization of physical/physiological processes and plant-soil-atmosphere interactions, and CSM input data including daily solar radiation, minimum and maximum air temperatures, precipitation, and windspeed. Historical weather data are available at many U.S. weather stations. Crop production is estimated by incorporating location-specific weather data into the CSM. However, for locations lacking measured solar radiation data, SRMs can be used to estimate solar radiation, which can be incorporated (in lieu of measured solar radiation) into the CSM to run crop simulations for natural resource management.

Objectives of this research were to: (1) statistically assess SRM accuracy in predicting solar radiation and cotton yield; (2) assess the accuracy of several available SRMs and a new SRM (i.e. TmRnWn) in predicting solar radiation at 10 locations under various temporal-averaging schemes (TASs); and (3) illustrate the potential usefulness of these SRMs to crop growers and managers by assessing their accuracy in predicting cotton yield under rainfed (RF) and irrigated (IRR) conditions.

\section{MATERIALS AND METHODS}

Symbols used in this article are listed in Table 1.

2.1. Solar radiation $\left(\boldsymbol{I}_{\text {rad }}\right)$ models. Numerous SRMs describe the ratio of surface-incident solar radiation $\left(R_{\mathrm{g}}\right)$ to extraterrestrial (Angot) solar radiation at the top of the atmosphere $\left(R_{\mathrm{a}}\right)$ as a function of several weather parameters. In this study, $I_{\text {rad }}$ denotes surface-incident solar radiation (i.e. $I_{\text {rad }}=R_{\mathrm{g}}$ ). Seven SRMs were examined, including Angstrom (1924), Bristow \& Campbell (1984), and Allen (1997), 3 hybrid models each involving a combination of these models (i.e. Angstrom-BC, Angstrom-Allen, and BC-Allen), and a regression SRM (TmRnWn) developed by the current authors.

The Angstrom model describes a linear relationship between $R_{\mathrm{g}} / R_{\mathrm{a}}$ ratio and the ratio of actual ( $n$ ) to potential $(N)$ daylength:

$$
R_{\mathrm{g}} / R_{\mathrm{a}}=a+b(n / N)
$$

where $a$ and $b$ are empirical regression coefficients (Angstrom 1924). Angstrom initially suggested typical empirical values of $a=0.2$ and $b=0.5$ (which are the values used in this study), but model calibration at different locations by various researchers in later years (Penman 1948, Turc 1961, Bennett 1962, Davies 1965, Monteith 1966, Castillo \& Santibanez 1981) showed significant geographical variability in these 2 coefficients (Doorenbos \& Pruitt 1975). In their model application to 21 locations in Chile, Castillo \& Santibanez (1981) observed a range of empirical values ( $a=0.22$ to 0.29 and $b=0.44$ to 0.57 ) among these locations. In this study, both $a$ and $b$ were adjusted in $\mathrm{r}^{2}$ maximization (least squares error minimization) to obtain the curve of best fit.

The model of Bristow \& Campbell (1984) describes daily solar radiation as an exponential asymptotic function of daily temperature range $d \mathrm{~T}$ :

$$
R_{\mathrm{g}} / R_{\mathrm{a}}=A\left\{1-\exp \left[-B(d T)^{C}\right]\right\}
$$

where $d T=\left(T_{\max }-T_{\min }\right) ; T_{\max }$ and $T_{\min }$ are daily maximum and minimum air temperatures $\left({ }^{\circ} \mathrm{C}\right)$; and $A, B$, and $C$ are empirical regression coefficients. Asymptote $A$ represents the theoretical maximum (clear-day) radiation, whereas $B$ and $C$ govern the function's shape (i.e. sensitivity of $R_{\mathrm{g}} / R_{\mathrm{a}}$ to changes in $d T$ ). Typical values are $A=0.7, B=0.004$ to 0.010 , and $C=2.4$ (Bristow \& Campbell 1984), which were the values used in this study. Meza \& Varas (2000) observed geographical variations in $B$ from 0.00150 to 0.01944 
Table 1. Identification of nomenclature and symbols used in text

\begin{tabular}{|c|c|}
\hline Symbol & Name (units) \\
\hline$a_{0}$ & Empirical intercept coefficient in the linear regression equation \\
\hline$a_{1}$ & Empirical slope coefficient in the linear regression equation \\
\hline AED & Atmospheric evaporative demand \\
\hline CSM & Crop simulation model \\
\hline DL & Daylength $(\mathrm{h})$ \\
\hline EAP & Envelope of acceptable precision \\
\hline EPI & Environmental productivity index \\
\hline ET & Evapotranspiration \\
\hline FSQ & First square \\
\hline FBL & First bloom \\
\hline FOB & First open boll \\
\hline GOSSYM & Cotton growth simulation model \\
\hline GOS & Gossypium (cotton genus name) \\
\hline SYM & Simulation \\
\hline$I_{\text {rad }}$ & Daily or monthly mean solar radiation $\left(\mathrm{MJ} \mathrm{m}^{-2} \mathrm{~d}^{-1}\right)$ \\
\hline$I_{\text {rad,meas }}$ & Measured solar radiation \\
\hline$I_{\text {rad,pred }}$ & Solar radiation predicted by a given solar radiation model (SRM) \\
\hline IR & Irrigated conditions \\
\hline$K_{\mathrm{r}}$ & Function of atmospheric pressure $(P)$ \\
\hline$K_{\text {ra }}$ & Empirical coefficient \\
\hline LAI & Leaf area index \\
\hline LCS & Lack of correlation weighted by standard deviations \\
\hline LSRA & Linear least squares regression analysis \\
\hline MSD & Mean squared deviation \\
\hline MSV & Mean squared variance \\
\hline$N_{\mathrm{yr}}$ & Number of years simulated for a given location \\
\hline$P$ & Atmospheric pressure \\
\hline$P_{\mathrm{o}}$ & Sea-level pressure \\
\hline PNS & Photosynthesis \\
\hline PPT & Daily or monthly mean precipitation $\left(\mathrm{mm} \mathrm{d}^{-1}\right)$ \\
\hline $\mathrm{r}^{2}$ & Determination coefficient \\
\hline $\mathrm{RF}$ & Rainfed conditions \\
\hline SB & Squared bias \\
\hline SDSD & Squared difference between standard deviations \\
\hline SRM & Solar radiation model \\
\hline$T_{\text {avg }}$ & Average daily or monthly mean air temperature $\left({ }^{\circ} \mathrm{C}\right)$ \\
\hline$T_{\max }$ & Maximum daily or monthly mean air temperature $\left({ }^{\circ} \mathrm{C}\right)$ \\
\hline$T_{\min }$ & Minimum daily or monthly mean air temperature $\left({ }^{\circ} \mathrm{C}\right)$ \\
\hline TmRnWn & A regression-based solar radiation model \\
\hline $\operatorname{Tm}$ & Temperature \\
\hline $\mathrm{Rn}$ & Rain or precipitation \\
\hline Wn & Windspeed \\
\hline WIND & Daily or monthly mean windspeed $\left(\mathrm{km} \mathrm{d}^{-1}\right)$ \\
\hline$x$ & Independent variable in the linear regression equation \\
\hline$y$ & Dependent variable in the linear regression equation \\
\hline$Y$ & Yield $\left(\mathrm{kg} \mathrm{ha}^{-1}\right)$ \\
\hline$Y_{\text {sim,meas }}$ & GOSSYM-simulated yield driven by measured solar radiation \\
\hline$Y_{\text {sim,pred }}$ & GOSSYM-simulated yield driven by SRM-predicted solar radiation \\
\hline
\end{tabular}

budget, it is possible to obtain an empirical relationship between solar radiation and temperature variations. Higher solar radiation during the day (e.g. clear skies) produces greater differences between daytime and nighttime temperatures, since the absence of cloud cover enhances both downward surface-incident solar radiation during the day (increasing $T_{\max }$ ) and upward escape of terrestrial infrared radiation from the surface at night (decreasing $T_{\min }$ ).

The model of Allen (1997) describes a power-law relationship between daily solar radiation and monthly mean maximum and minimum temperatures $\left({ }^{\circ} \mathrm{C}\right)$ :

$$
R_{\mathrm{g}} / R_{\mathrm{a}}=K_{\mathrm{r}}\left(T_{\max }-T_{\min }\right)^{0.5}
$$

where $K_{\mathrm{r}}$ is a function of atmospheric pressure $P: K_{\mathrm{r}}=K_{\mathrm{ra}}\left(P / P_{\mathrm{o}}\right)^{0.5}, K_{\mathrm{ra}}$ is an empirical coefficient, and $P_{\mathrm{o}}$ is sealevel pressure $\left(P_{\mathrm{o}}=101.325 \mathrm{kPa}\right)$. Typical values of $K_{\text {ra }}$ are 0.17 and 0.20 for interior and coastal regions, respectively (Allen 1997). Meza \& Varas (2000) observed geographical variations in $K_{\text {ra }}$ from 0.0114 to 0.4717 across 21 Chilean locations. In this study, $P$ was assumed equal to $P_{\text {oi }}$ and $K_{\text {ra }}$ was adjusted to obtain the curve of best fit.

The 3 hybrid models (Angstrom-BC, Angstrom-Allen, and BC-Allen) incorporate functional algorithms of 2 of the 3 above-described models (Eqs. 1 to $3)$, to potentially improve model flexibility (by increasing the number of empirical coefficients, parameters, and degrees of freedom), accuracy, and reliability in predicting solar radiation. The Angstrom model (Eq. 1) incorporates one parameter (daylength), whereas the BristowCampbell (Eq. 2) and Allen (Eq. 3)

across 21 Chilean locations. In this study, $A$ and $C$ were fixed at 0.7 and 2.4, respectively; and $B$ was adjusted to obtain the curve of best fit. The BristowCampbell model (Eq. 2) is based on the energy budget at the earth's surface, the partitioning of incoming solar radiation to various heat terms (e.g. sensible and latent heats, terrestrial infrared radiation), and the daily Bowen ratio (Bristow \& Campbell 1984). Since air temperature is governed by the earth's surface energy models each incorporate 2 parameters $\left(T_{\min }\right.$ and $\left.T_{\max }\right)$. Thus, the hybrid BC-Allen model (a weighted average of Eqs. 2 \& 3 ) similarly contains 2 parameters ( $T_{\min }$ and $T_{\max }$ ), whereas the hybrid Angstrom-BC model (a weighted average of Eqs. 1 \& 2) and Angstrom-Allen model (a weighted average of Eqs. 1 \& 3) each contain 3 parameters (daylength, $T_{\min }$ and $T_{\max }$ ).

A new SRM (TmRnWn) is introduced in this study and compared with the other SRMs for relative solar 
radiation estimation accuracy. The TmRnWn model is a linear regression model that incorporates $T_{\min }\left({ }^{\circ} \mathrm{C}\right)$, $T_{\max }\left({ }^{\circ} \mathrm{C}\right)$, precipitation (PPT, $\mathrm{mm} \mathrm{d}^{-1}$ ), and windspeed (WIND, $\mathrm{km} \mathrm{d}^{-1}$ ) into a flexible functional algorithm describing $I_{\text {rad }}\left(\mathrm{MJ} \mathrm{m}^{-2} \mathrm{~d}^{-1}\right)$ :

$$
I_{\text {rad }}=a_{0}+a_{1} \cdot T_{\text {min }}+a_{2} \cdot T_{\max }+a_{3} \cdot \mathrm{PPT}+a_{4} \cdot \text { WIND }
$$

In calibrating the TmRnWn SRM, empirical regression coefficients $\left(a_{0}, a_{1}, a_{2}, a_{3}, a_{4}\right)$ were derived from historical weather data from Stoneville, Mississippi, via linear least squares regression analysis (LSRA), and the calibrated model was then applied to the Stoneville data (a 'fudged' validation) as well as the other 9 locations ('pure' validation) to assess model performance accuracy in predicting $I_{\text {rad. }}$. The advantage of the TmRnWn model over the other 6 SRMs is its superior flexibility as a result of incorporating 4 weather parameters $\left(T_{\min }, T_{\max }, \mathrm{PPT}\right.$, and WIND) and 5 adjustable parameters, whereas the other SRMs contain fewer weather parameters ( $T_{\min }, T_{\max }$ and/or daylength) and only 1 to 3 adjustable parameters. Increasing the number of adjustable parameters increases degrees of freedom, flexibility, and hence model performance (as reflected in increased $\mathrm{r}^{2}$ ).

2.2. The GOSSYM cotton growth model. Cotton (Gossypium hirsutum L., Upland midseason variety) simulations were conducted in this study using GOSSYM, a previously validated dynamic, physical, physiological, phenological, mechanistic, processlevel, material-balance, cotton growth model (Baker et al. 1983, Reddy et al. 1997, Hodges et al. 1998). The name 'GOSSYM' is derived from 'GOS', for Gossypium (a cotton genus name), and 'SYM', for simulation. Driven by input data for geography, daily weather, soil type and hydrology, management practices, and cultivar properties, GOSSYM uses a daily time step to simulate cotton growth, phenology, and yield during the growing season. GOSSYM calculates the dates and durations of various phenostages, including first square (FSQ), first bloom (FBL), first open boll (FOB), and time to maturity. Other calculated parameters include plant height, mainstem node number, leaf area index (LAI), biomass accumulation (for whole plant and individual organs), number of plant organs, vegetative and fruiting branches, inter-organ partitioning of photoassimilates and nutrients, and number of waterand N-stress days during the growing season. GOSSYM incorporates the environmental productivity index (EPI) concept, which is a measure of the magnitude of a particular environmental stress in reducing actual growth/photosynthesis below the potential value: EPI values range from 0 (maximum stress) to 1 (zero stress). To assess water and nutrient status, GOSSYM formulates material balances and calculates supply:demand ratios for water, carbon, and nitrogen.
Additional information on GOSSYM and its subroutines is discussed in Baker et al. (1983) and Hodges et al. (1998).

2.3. Historical weather data. Historical weather data for daily $I_{\text {rad }}, T_{\min }$ and $T_{\max }$, PPT, and WIND were collected from 10 weather stations across the U.S. Cotton Belt: Stoneville, Mississippi; Meridianville, Alabama; Shafter, California; Corpus Christi, Texas; Florence, South Carolina; Lubbock, Texas; Artesia, New Mexico; Maricopa, Arizona; Portageville, Missouri; and Springfield, Illinois. Daily average temperature $\left(T_{\text {avg }}\right)$ was calculated as a weighted arithmetic average of daily $T_{\min }$ and $T_{\max }: T_{\text {avg }}=(\mathrm{DL} / 24) \cdot T_{\max }+[(24-\mathrm{DL}) / 24] \cdot T_{\min }$ where $\mathrm{DL}=$ daylength $(\mathrm{h})$, which varies with latitude, time of year, and solar declination angle. Locations, years, geographical coordinates (longitude and latitude), and prevalent soil types for each location are summarized in Table 2. Locations were chosen for their proximity to reliable weather stations and to assess geographical and associated climatic variabilities in weather parameters, cotton yield, and cotton response to the environment. Years for each location were chosen based on historical weather data availability. Predicted datasets were generated for each SRM by applying its algorithm to calculate daily $I_{\text {rad }}$ from historical (measured) daily air temperatures and/or precipitation and windspeed (depending on the SRM). For each SRM, $I_{\text {rad }}$ estimation accuracy was assessed by regressing daily predicted $I_{\text {rad }}$ versus measured $I_{\text {radi }}$ and yield estimation accuracy was assessed by regressing GOSSYM yields driven by measured $I_{\text {rad }}$ versus yields driven by SRM-predicted $I_{\text {rad }}$.

2.4. GOSSYM simulations. Driven by weather, initial soil fertility and hydrology, management, and cultivar input data, GOSSYM simulated cotton yield at 10 locations (Table 2). Simulations were conducted from 1 May to 31 October (183 d growing season) under ambient atmospheric $\mathrm{CO}_{2}$ concentration (360 $\mu \mathrm{ll}^{-1}$ ) and optimal (stress-free) environmental conditions. Management practices included a single pre-planting $\mathrm{N}$ fertilizer application of $202 \mathrm{~kg} \mathrm{ha}^{-1}$, a $96.5 \mathrm{~cm}$ row spacing, and a planting density of 101894 plants ha ${ }^{-1}$. For the irrigation simulations, 0.75 in $(1.905 \mathrm{~cm})$ irrigation water was applied via sprinkler on days when the daily drought stress index decreased below 0.75 , reflecting significant drought stress. Environmental conditions and management practices used in the simulations are summarized in Table 2. Baseline simulations involved running GOSSYM with daily historical solar radiation $\left(I_{\text {rad,meas }}\right)$. To assess yield estimation accuracy of a given SRM and TAS, the $I_{\text {rad,meas }}$ input dataset was replaced with the SRM-generated solar radiation $\left(I_{\text {rad,pred }}\right)$ dataset; and simulated yields driven by $I_{\text {rad,pred }}$ for the given SRM were compared with simulated yields driven by $I_{\text {rad,meas }}$. Technological trends in 
Table 2. Geographical locations, environmental conditions, and management practices used in the GOSSYM cotton simulations

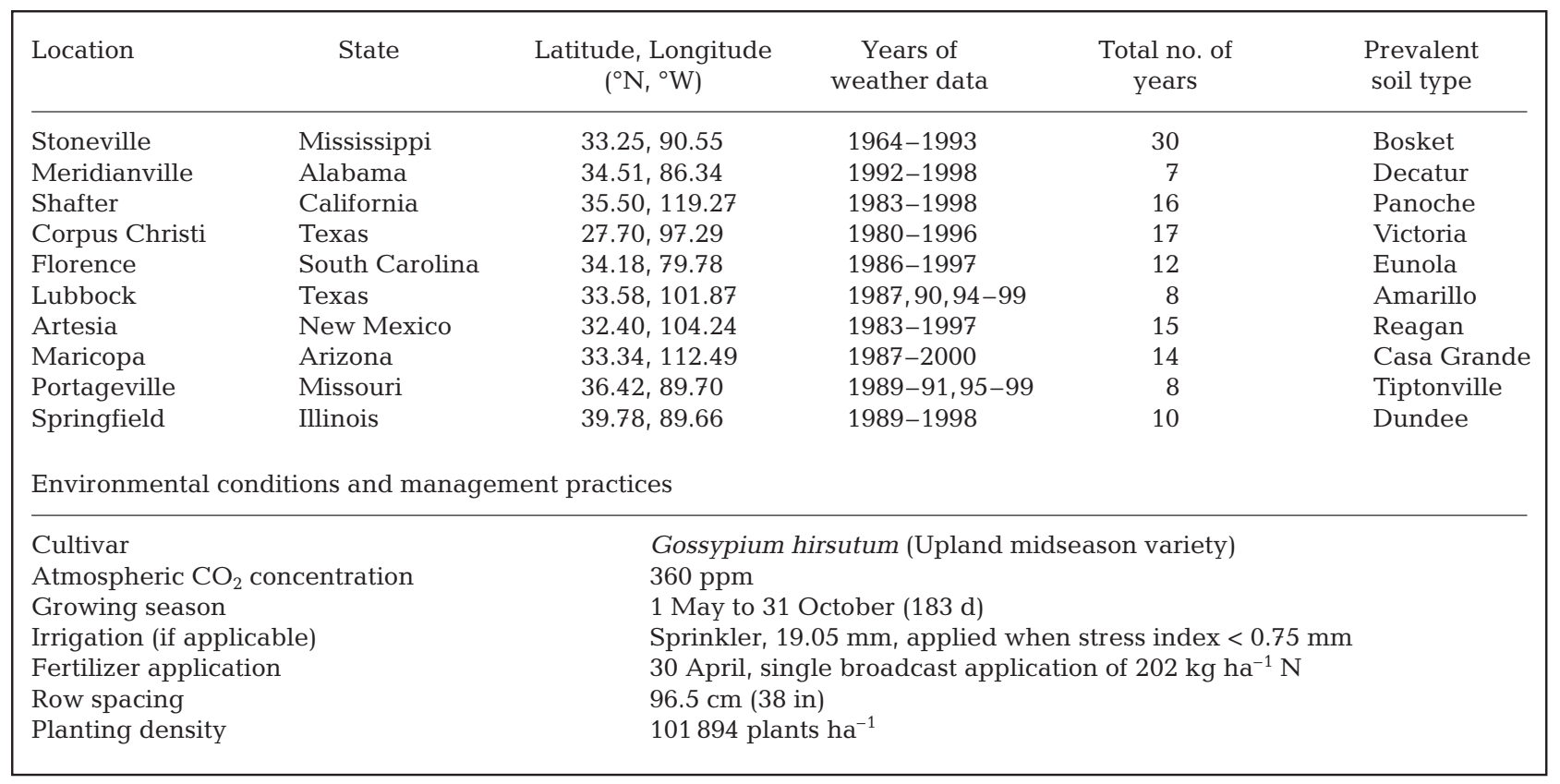

yield were removed in the GOSSYM simulations. For example, cotton cultivar and fertilization rates were held constant; and no pesticides, plant growth regulators, liming, or soil amendments were used in the simulations.

2.5. Temporal-averaging schemes. Each SRM contains an empirical algorithm describing $I_{\text {rad }}$ as a function of environmental parameters such as daylength (Angstrom model), $T_{\min }$ and $T_{\max }$ (Bristow-Campbell and Allen models), a combination of these parameters (3 hybrid models), or a combination of $T_{\min }, T_{\text {max }}, \mathrm{PPT}$, and WIND (TmRnWn model). These parameters can be defined and expressed on various time scales (e.g. diurnal, monthly mean, annual mean, or interannual averages) for use in the SRMs. Temporal averaging, conducted as an academic exercise, smooths out short-term fluctuations by averaging extreme-weather days with normal days, thus reducing the weather parameters' variability, which is expected to improve SRM estimations. Temporal variability decreases as time scale of temporal averaging increases. Daily parameters show greater variability (due to extreme weather events) than monthly means, the latter of which average anomalous effects of a few extreme-weather days with more numerous normal-weather days over the month.

In generating an $I_{\text {rad,pred }}$ dataset, a given SRM calculates $I_{\text {rad }}$ for all 365 days of each year examined for each location (Table 3). However, coefficient values in the SRM's algorithm depend on the TAS (e.g. daily, monthly mean, interannual average) used in calculating the weather parameters. Four TASs were exam- ined with each of the 7 SRMs via a box factorial experimental design, generating $4 \times 7=28$ scenarios (Table 3). Scheme 1, involving no temporal averaging, incorporates daily measured weather parameters into the SRM's algorithm to calculate daily $I_{\text {rad }}$. To calculate the SRM's coefficients, daily measured $I_{\text {rad }}$ was regressed against the SRM-specific function of relevant daily measured weather parameters. The number of data points on the plot is $365 \times N_{\mathrm{yr}}$, where $N_{\mathrm{yr}}$ is the number of years examined for the given location (Table 3). LSRA was applied to generate a curve of best fit, from which the SRM's coefficients were calculated, yielding an empirical algorithm describing $I_{\text {rad }}$ as a function of other weather parameters.

Scheme 2 involved monthly averaging, in which monthly means were calculated from daily measured weather parameters. Monthly mean $I_{\text {rad }}$ was regressed against the SRM-specific function of monthly mean weather parameters, yielding a plot with $12 \times N_{\mathrm{yr}}$ data points. In Scheme 3, interannual averaging was conducted by averaging daily measured weather parameters over $N_{\mathrm{yr}}$ to obtain interannual averages for each day of the year. These 365 interannual average daily $I_{\text {rad }}$ values were regressed against the SRMspecific function of interannual average daily weather parameters, yielding a plot with 365 data points. Scheme 4 involved both monthly and interannual averaging, in which monthly means were averaged over $N_{\text {yr }}$ (analogous to Scheme 3), to obtain interannual averages for each month of the year. These 12 interannual average monthly mean $I_{\text {rad }}$ values were regressed 
Table 3. Linear (LSRA) regression coefficients, determination coefficients $\left(\mathrm{r}^{2}\right)$, mean square variance and deviation coefficients (MSV, MSD, SB, SDSD, LCS) for predicted versus measured solar radiation, for the given solar radiation model and temporal-averaging scheme, for the geographical composite. Daily predicted solar radiations were calculated from algorithms describing daily solar radiation for each year $\left(y=a_{0}+a_{1} \cdot x_{1}\right)$, where $y=$ solar radiation estimated by the given solar radiation model $\left(\mathrm{MJ} \mathrm{m}^{-2} \mathrm{~d}^{-1}\right)$ and $\mathrm{x}_{1}=$ observed solar radiation $\left(\mathrm{MJ} \mathrm{m}^{-2} \mathrm{~d}^{-1}\right)$. See Table 1 for definitions

\begin{tabular}{|c|c|c|c|c|c|c|c|c|c|c|c|c|c|c|c|c|}
\hline $\begin{array}{l}\text { Solar radiation } \\
\text { model }\end{array}$ & $a_{0}$ & $a_{1}$ & $\mathrm{r}^{2}$ & MSV & MSD & $\begin{array}{l}\text { SB/ } \\
\text { MSD }\end{array}$ & $\begin{array}{l}\text { SDSD/ } \\
\text { MSD }\end{array}$ & $\begin{array}{l}\text { LCS/ } \\
\text { MSD }\end{array}$ & $a_{0}$ & $a_{1}$ & $r^{2}$ & MSV & MSD & $\begin{array}{l}\text { SB/ } \\
\text { MSD }\end{array}$ & $\begin{array}{l}\text { SDSD/ } \\
\text { MSD }\end{array}$ & $\begin{array}{l}\text { LCS/ } \\
\text { MSD }\end{array}$ \\
\hline & \multicolumn{8}{|c|}{ Scheme 1 (50 005 data points) } & \multicolumn{8}{|c|}{ Scheme 2 (1644 data points) } \\
\hline Angstrom & 6.830 & 0.606 & 0.600 & 25.396 & 25.396 & 0.000 & 0.118 & 0.882 & 1.187 & 0.932 & 0.927 & 2.911 & 2.911 & 0.000 & 0.015 & 0.985 \\
\hline Bristow-Campbell & 7.217 & 0.574 & 0.614 & 24.624 & 24.645 & 0.001 & 0.184 & 0.815 & 2.521 & 0.844 & 0.913 & 3.695 & 3.724 & 0.008 & 0.146 & 0.846 \\
\hline Allen & 7.256 & 0.571 & 0.615 & 24.627 & 24.653 & 0.001 & 0.190 & 0.809 & 2.475 & 0.847 & 0.914 & 3.638 & 3.668 & 0.008 & 0.143 & 0.849 \\
\hline Angstrom-BC & 6.436 & 0.629 & 0.626 & 23.743 & 23.744 & 0.000 & 0.112 & 0.888 & 1.195 & 0.931 & 0.928 & 2.881 & 2.881 & 0.000 & 0.016 & 0.984 \\
\hline Angstrom-Allen & 6.447 & 0.628 & 0.626 & 23.732 & 23.732 & 0.000 & 0.113 & 0.887 & 1.186 & 0.931 & 0.928 & 2.870 & 2.870 & 0.000 & 0.016 & 0.984 \\
\hline BC-Allen & 7.187 & 0.576 & 0.616 & 24.506 & 24.529 & 0.001 & 0.184 & 0.815 & 2.415 & 0.851 & 0.914 & 3.607 & 3.633 & 0.007 & 0.134 & 0.858 \\
\hline \multirow[t]{2}{*}{ TmRnWn } & 6.282 & 0.630 & 0.652 & 22.085 & 22.097 & 0.001 & 0.139 & 0.861 & 1.389 & 0.916 & 0.936 & 2.595 & 2.600 & 0.002 & 0.044 & 0.954 \\
\hline & \multicolumn{8}{|c|}{ Scheme 3 (3650 data points) } & \multicolumn{8}{|c|}{ Scheme 4 (120 data points) } \\
\hline Angstrom & 1.114 & 0.936 & 0.924 & 3.123 & 3.123 & 0.000 & 0.009 & 0.991 & 0.088 & 0.996 & 0.988 & 0.438 & 0.438 & 0.001 & 0.000 & 0.999 \\
\hline Bristow-Campbell & 2.298 & 0.857 & 0.910 & 3.814 & 3.833 & 0.005 & 0.110 & 0.885 & 1.192 & 0.922 & 0.977 & 0.998 & 1.017 & 0.019 & 0.167 & 0.814 \\
\hline Allen & 2.187 & 0.864 & 0.912 & 3.732 & 3.750 & 0.005 & 0.099 & 0.896 & 1.223 & 0.920 & 0.976 & 1.040 & 1.061 & 0.021 & 0.169 & 0.811 \\
\hline Angstrom-BC & 1.110 & 0.937 & 0.926 & 3.050 & 3.050 & 0.000 & 0.010 & 0.990 & 0.010 & 1.000 & 0.991 & 0.361 & 0.362 & 0.001 & 0.003 & 0.997 \\
\hline Angstrom-Allen & 1.104 & 0.937 & 0.926 & 3.037 & 3.037 & 0.000 & 0.010 & 0.990 & 0.018 & 1.000 & 0.991 & 0.345 & 0.345 & 0.001 & 0.002 & 0.997 \\
\hline BC-Allen & 2.118 & 0.869 & 0.913 & 3.656 & 3.672 & 0.004 & 0.092 & 0.903 & 0.841 & 0.945 & 0.977 & 0.891 & 0.899 & 0.009 & 0.080 & 0.911 \\
\hline TmRnWn & 1.095 & 0.935 & 0.937 & 2.587 & 2.587 & 0.000 & 0.019 & 0.981 & 0.142 & 0.991 & 0.994 & 0.238 & 0.239 & 0.001 & 0.006 & 0.993 \\
\hline
\end{tabular}

against the SRM-specific function of interannual average monthly mean weather parameters, yielding a plot with 12 data points. For each of these 4 TASs, LSRA was applied. Similar TASs were conducted by Meza \& Varas (2001), who applied the Angstrom and Allen models to both daily and mean monthly weather data, and the Bristow-Campbell model to only the daily data, to predict solar radiation at 21 Chilean locations.

In summary, empirical regression plots for Schemes $1,2,3$, and 4 contain $365 \times N_{\mathrm{yr}}, 12 \times N_{\mathrm{yr}}, 365$, and 12 data points, respectively (Table 3 ). For the geographical composite, $N_{\mathrm{yr}, \mathrm{comp}}$ is equal to the number of years examined for each location, summed over all 10 locations (i.e. $N_{\mathrm{yr}, \mathrm{comp}}=137 \mathrm{yr}$ ). Thus, the composite plots contain $50005(=137 \times 365), 1644(=137 \times 12), 3650$ $(=365 \times 10)$, and $120(=12 \times 10)$ data points for Schemes 1, 2, 3, and 4, respectively. Algorithms describing daily $I_{\text {rad }}$ versus other relevant measured parameters were generated for all 28 scenarios. The algorithm was applied to the historical daily weather data to calculate daily predicted $I_{\text {rad }}\left(I_{\text {rad,pred }}\right)$ from relevant daily measured weather parameters, generating a daily $I_{\text {rad,pred }}$ dataset for each scenario and location.

2.6. Statistical methods for scenario performance assessment. Three statistical methods were used to assess the empirical algorithm of each scenario for $I_{\text {rad }}$ and cotton yield estimation accuracies at each location as well as the geographical composite: (1) LSRA; (2) deviation-based graphical analysis using an envelope of acceptable precision (EAP) of $15 \%$ (Reddy \& Boone 2002); (3) mean-squared-deviation (MSD) method of Kobayashi \& Salaam (2000).
To assess scenario accuracy in predicting $I_{\text {rad, }} I_{\text {rad,pred }}$ $\left(\mathrm{MJ} \mathrm{m}^{-2} \mathrm{~d}^{-1}\right)$ for each scenario was regressed against measured $I_{\text {rad }}\left(I_{\text {rad,meas }}, \mathrm{MJ} \mathrm{m}^{-2} \mathrm{~d}^{-1}\right): I_{\text {rad,pred }}=a_{\mathrm{o}}+a_{1}$

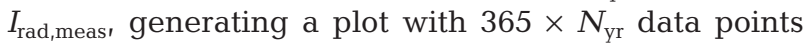
(e.g. $N_{\mathrm{yr}}=30$ and $137 \mathrm{yr}$ for Stoneville and the geographical composite, respectively). Scenario performance was assessed by evaluating the regression coefficients $\left(a_{0}, a_{1}\right)$ and coefficient of determination $\left(\mathrm{r}^{2}\right)$. To account for differences in numbers of data points and parameters, the adjusted $\mathrm{r}^{2}$ is used to provide a standard baseline for comparison. The closer the values of $a_{0}, a_{1}$, and $r^{2}$ to 0,1 , and 1 , respectively the greater the scenario's estimation accuracy. Deviations from these ideal values reflect data scatter, decreased scenario accuracy, and/or invalid concepts used in SRM development. Regression plots of $I_{\text {rad,pred }}$ versus $I_{\text {rad, meas, as }}$ well as deviation plots of $I_{\text {rad,pred }}-I_{\text {rad,meas }}$ versus $I_{\text {rad,meas, }}$ were constructed. In the deviation plots, the greater the relative number of data points within the EAP (15\% error), the more accurate is the given scenario.

To assess scenario accuracy in predicting yield, 2 sets of GOSSYM simulations were conducted: (1) using $I_{\text {rad,pred }}$ to simulate scenario-predicted yield $\left(Y_{\text {sim,pred }}\right)$; and (2) using $I_{\text {rad,meas }}$ to simulate yield based on measured $I_{\text {rad }}\left(Y_{\text {sim,meas }}\right)$. Simulations were conducted under both rainfed $(\mathrm{RF})$ and irrigated (IRR) conditions. For each scenario, $Y_{\text {sim,pred }}\left(\mathrm{kg} \mathrm{ha}^{-1}\right)$ was regressed against $Y_{\text {sim,meas }}\left(\mathrm{kg} \mathrm{ha}^{-1}\right): Y_{\text {sim,pred }}=b_{\mathrm{o}}+b_{1} Y_{\text {sim,meas }}$ generating a plot with $2 \times N_{\mathrm{yr}}$ data points (accounting for both RF and IRR yields). Separate linear regressions were conducted using RF data only, IRR data only, and both RF and IRR (RF + IRR) data. For each regression, $b_{0}, b_{1}$, 
and $\mathrm{r}^{2}$ were calculated, and compared to assess scenario performance. Regression plots of $Y_{\text {sim,pred }}$ versus $Y_{\text {sim,meas }}$ and deviation plots of $Y_{\text {sim,pred }}-Y_{\text {sim,meas }}$ versus $Y_{\text {sim,meas }}$, were constructed for each scenario.

In summary, accuracies of 28 scenarios in predicting $I_{\text {rad }}$ and yield were assessed via a 3-step regression process. Algorithms were derived by regressing measured $I_{\text {rad }}$ versus relevant measured weather parameters in the first step, and these algorithms were then applied to the measured weather datasets to generate $I_{\text {rad,pred, }}$ which was regressed against $I_{\text {rad,meas }}$ in the second step. Each scenario was thus characterized by a specific $I_{\text {rad }}$ estimation accuracy for the given location and the geographical composite. This accuracy was then propagated to the third step, which involved running GOSSYM using both $I_{\text {rad,pred }}$ and $I_{\text {rad,meas, }}$ and regressing $I_{\text {rad,pred-driven yields }}\left(Y_{\text {sim,pred }}\right)$ against $I_{\text {rad,meas }}$-driven yields $\left(Y_{\text {sim,meas }}\right)$. Errors in $I_{\text {rad }}$ estimations were propagated and reflected in the yield estimations. Thus, a given scenario's yield estimation accuracy depends in part on its $I_{\text {rad }}$ estimation accuracy, as well as on yield response (sensitivity) to changes in $I_{\text {rad }}$ as parameterized in GOSSYM.

Using the statistical MSD-based approach of Kobayashi \& Salaam (2000), the ratios of squared bias (SB) to MSD, of squared difference between standard deviations (SDSD) to MSD, and of lack of correlation weighted by standard deviations (LCS) to MSD were calculated, where MSD correlates negatively with the degree of agreement between simulation and measurement:

$$
\mathrm{MSD}=\operatorname{SUM}\left(x_{i}-y_{i}\right)^{2} / n=\mathrm{SB}+\mathrm{SDSD}+\mathrm{LCS}
$$

where SUM denotes a summation, $x_{i}=$ predicted or estimated solar radiation $\left(\mathrm{MJ} \mathrm{m} \mathrm{m}^{-2} \mathrm{~d}^{-1}\right.$ ) or yield ( $\mathrm{kg}$ $\left.\mathrm{ha}^{-1}\right), y_{i}=$ measured solar radiation $\left(\mathrm{MJ} \mathrm{m}^{-2} \mathrm{~d}^{-1}\right)$ or yield $\left(\mathrm{kg} \mathrm{ha}^{-1}\right), i=$ index denoting day, month, or year (depending on TAS), and $n=$ number of data points. The SB represents the bias of the estimate from the measurement:

$$
\mathrm{SB}=\left(y_{\mathrm{bar}}-x_{\mathrm{bar}}\right)^{2}
$$

where 'bar' denotes average value. The SDSD represents the difference in magnitude of fluctuation between estimate and measurement, and correlates negatively with the scenario's ability to simulate the fluctuation magnitude:

$$
\begin{gathered}
\mathrm{SD}_{\mathrm{s}}=\left[\operatorname{SUM}\left(x_{i}-x_{\mathrm{bar}}\right)^{2} / n\right]^{0.5} \\
\mathrm{SD}_{\mathrm{m}}=\left[\operatorname{SUM}\left(y_{i}-y_{\mathrm{bar}}\right)^{2} / n\right]^{0.5} \\
\mathrm{SDSD}=\left(\mathrm{SD}_{\mathrm{s}}-\mathrm{SD}_{\mathrm{m}}\right)^{2}
\end{gathered}
$$

where $\mathrm{SD}_{\mathrm{s}}$ and $\mathrm{SD}_{\mathrm{m}}$ are the standard deviations of the estimate $\left(x_{i}\right)$ and the measurement $\left(y_{i}\right)$, respectively, about their respective average values ( $x_{\text {bar }}$ and $\left.y_{\text {bar }}\right)$.
The LCS term correlates negatively with the scenario's ability to simulate the fluctuation pattern across the number of measurements:

$$
\mathrm{LCS}=2 \mathrm{SD}_{\mathrm{s}} \cdot \mathrm{SD}_{\mathrm{m}} \cdot(1-r)
$$

where $r=$ correlation coefficient between estimate and measurement. Mean squared variance (MSV) is:

$$
\mathrm{MSV}=\mathrm{SDSD}+\mathrm{LCS}=\mathrm{MSD}-\mathrm{SB}
$$

For each scenario, the LSRA slope, intercept, $\mathrm{r}^{2}$, SB/MSD, SDSD/MSD, and LCS/MSD ratios were calculated for the 10 locations and the geographical composite to assess performance in predicting solar radiation and yield. These statistical methods assess scenario accuracy and identify sources of variation between estimations ( $\left.I_{\text {rad,pred, }} \mathrm{Y}_{\text {sim,pred }}\right)$ and measurements $\left(I_{\text {rad,meas, }}, \mathrm{Y}_{\text {sim,meas }}\right)$.

\section{RESULTS AND DISCUSSION}

\subsection{Empirical relationships between solar radiation and weather parameters}

For each SRM, the Angstrom model predicted a negative correlation between $I_{\text {rad }}$ and inverse daylength (i.e. positive correlation with daylength); and the Bristow-Campbell and Allen models predicted a positive correlation between $I_{\text {rad }}$ and air temperature range (i.e. difference between $T_{\max }$ and $T_{\min }$ on daily/monthly time scales). That is, $I_{\text {rad }}$ increased as both daylength and $T_{\max }-T_{\min }$ increased. This correlation depended on time of year. High $I_{\text {rad }}$ is associated with clear skies, which allow high solar (visible) radiation to reach the earth's surface (due to a high direct/diffuse radiation ratio), allowing rapid warming of the surface and atmosphere (high $T_{\max }$ ), but which also allow terrestrial infrared radiation to escape into space at night, allowing rapid cooling of the surface and atmosphere (low $\left.T_{\min }\right)$, resulting in a large $\left(T_{\max }-T_{\min }\right)$ range. Conversely, cloudy skies (low $I_{\text {rad }}$ ) reduce daytime surfaceincident solar radiation (due to a low direct/diffuse radiation ratio), generating a lower warming rate (lower $T_{\max }$ ), and also absorb and emit more terrestrial radiation at night, restricting the cooling rate (higher $T_{\min }$ ), resulting in a lower $T_{\max }-T_{\min }$ range. This physical reasoning, describing physical (not just statistical) relationships among weather parameters (e.g. $I_{\text {rad }}$ versus a function of air temperatures) justifies the choice of specific weather parameters in the various SRMs (e.g. use of temperature range $T_{\max }-T_{\min }$ in the Allen model, as opposed to only $T_{\min }$ or only $T_{\max }$ ).

Results of this study are in reasonable agreement with those of other studies, which similarly observed negative correlations between $I_{\text {rad }}$ and daylength for 
the Angstrom model (Angstrom 1924, Penman 1948, Turc 1961, Bennett 1962, Davies 1965, Monteith 1966, Castillo \& Santibanez 1981), and positive correlations between $I_{\text {rad }}$ and temperature range $T_{\max }-T_{\min }$ for the Bristow-Campbell model (Bristow \& Campbell 1984) and Allen model (Allen 1995, 1997). In this study, optimal coefficients for each SRM varied significantly with geography, as observed in these other studies and in Meza \& Varas (2001) and Doorenbos \& Pruitt (1975). Mahmood \& Hubbard (2002) observed a seasonal bias in $I_{\text {rad }}$ estimations from temperature in the Northern Great Plains.

\subsection{Solar radiation estimations}

Linear regression coefficients $\left(a_{0}, a_{1}\right)$ from plots of $I_{\text {rad,pred }}$ versus $I_{\text {rad,meas }}$ were calculated for the $7 \mathrm{SRMs}$, 4 TASs, 10 locations, and the geographical composite. The MSV, MSD, and the SB/MSD, SDSD/MSD, and LCS/MSD ratios were also calculated. For the sake of brevity, only the geographical composites are summarized in Table 3. Geographical composite regression plots for the 7 SRMs are shown in Figs. 1, 2, \& 3 for Schemes 2, 3, and 4, respectively. Analogous plots for the 10 locations were omitted for clarity; and plots for Scheme 1 were omitted due to the extremely large number of data points (50005) on the geographical composite plots. The $I_{\text {rad }}$ estimation accuracy depended on TAS, SRM, and location.

3.2.1. Temporal-averaging effects. Higher $r^{2}$ reflects decreased data scatter and increased scenario accuracy. For a given SRM and location, $\mathrm{r}^{2}$ for $I_{\text {rad }}$ estimations was lowest for Scheme 1 and highest for Scheme 4, showing temporal averaging effects of smoothing out short-term fluctuations and associated $I_{\text {rad }}$ variability (i.e. reducing temporal scatter). For Scheme 1, the geographical composite $r^{2}$ ranged from 0.600 (Angstrom model) to 0.652 (TmRnWn model) (Table 3), suggesting a moderate (though relatively weak) correlation between $I_{\text {rad,pred }}$ and $I_{\text {rad,meas. }}$ Improved results in daily $I_{\text {rad }}$ predictions were obtained in the application of the Bristow-Campbell model (Bristow \& Campbell 1984) in the Great Plains (Mahmood \& Hubbard 2002). In contrast to Scheme 1, the geographical composite $\mathrm{r}^{2}$ for Scheme 4 ranged from 0.976 (Allen model) to 0.994 (TmRnWn model), showing reduced scatter in the $I_{\text {rad }}$ data and a stronger correlation between $I_{\text {rad,pred }}$ and $I_{\text {rad,meas, }}$ as a result of doubletemporal averaging (i.e. interannual averaging of

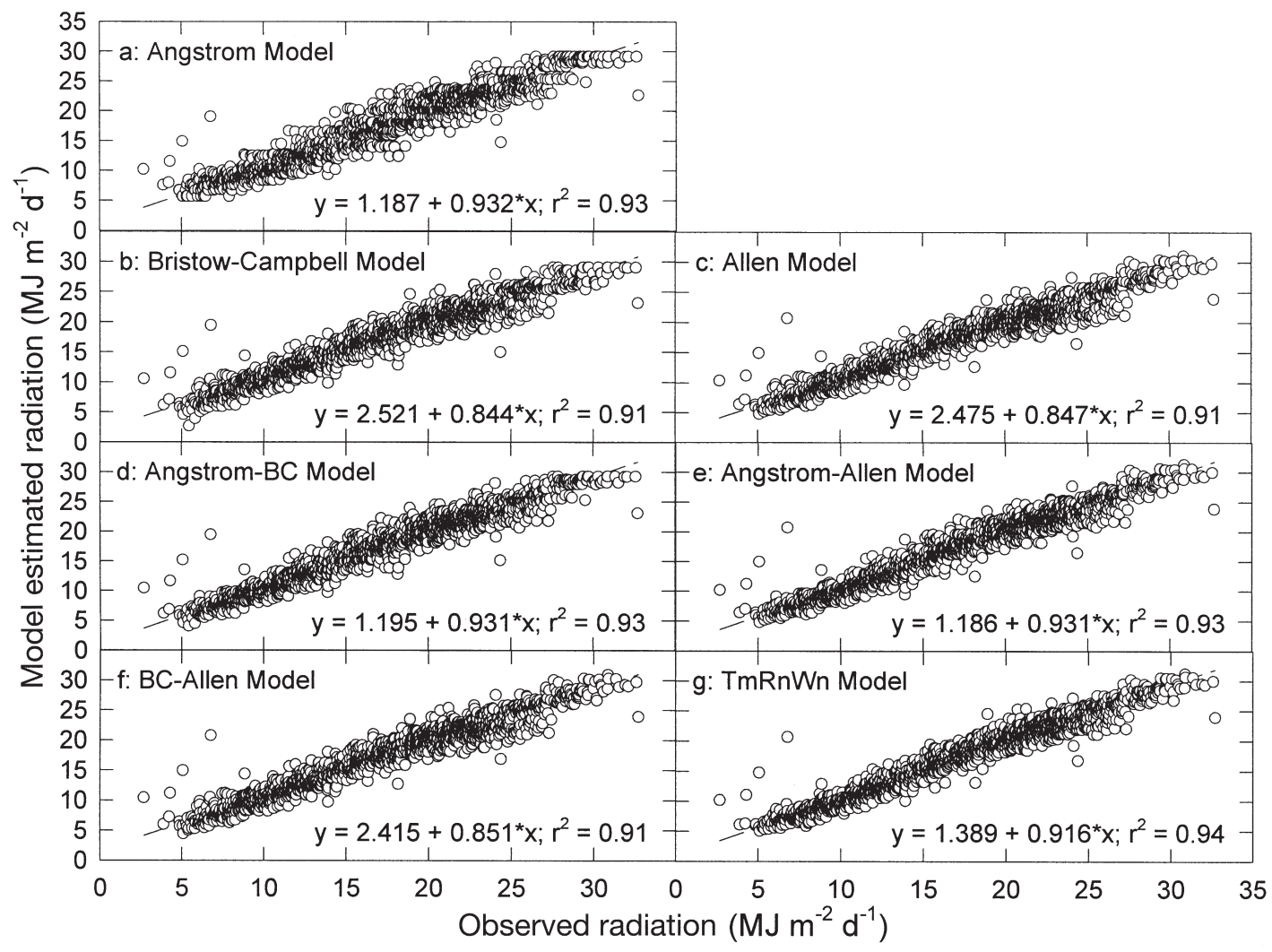

Fig. 1. Regression plots of model estimated versus observed solar radiation across 10 locations, for 7 solar radiation models and Scheme 2 (monthly averaging) 


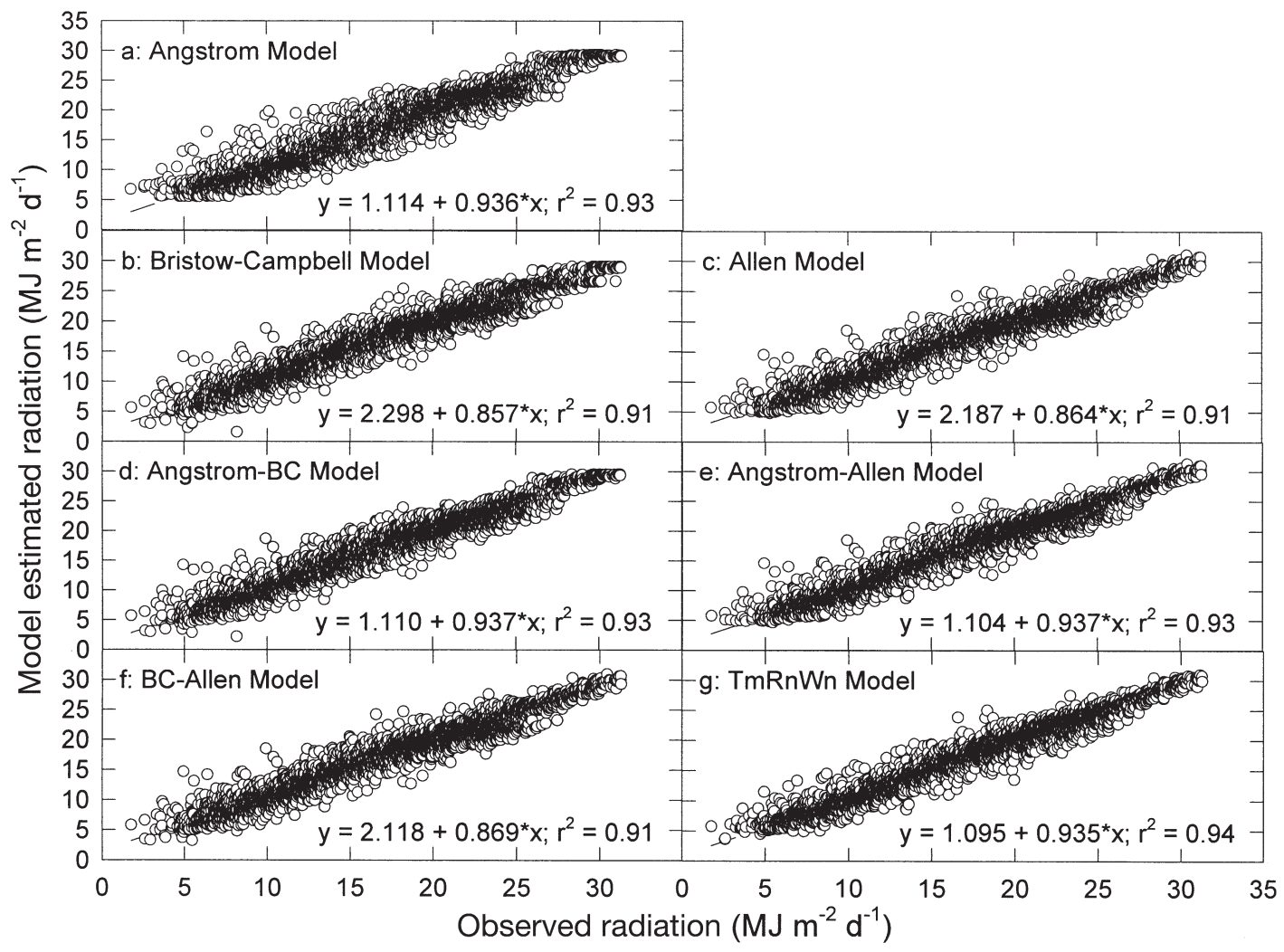

Fig. 2. Regression plots of model estimated versus observed solar radiation across 10 locations, for 7 solar radiation models and Scheme 3 (interannual averaging)

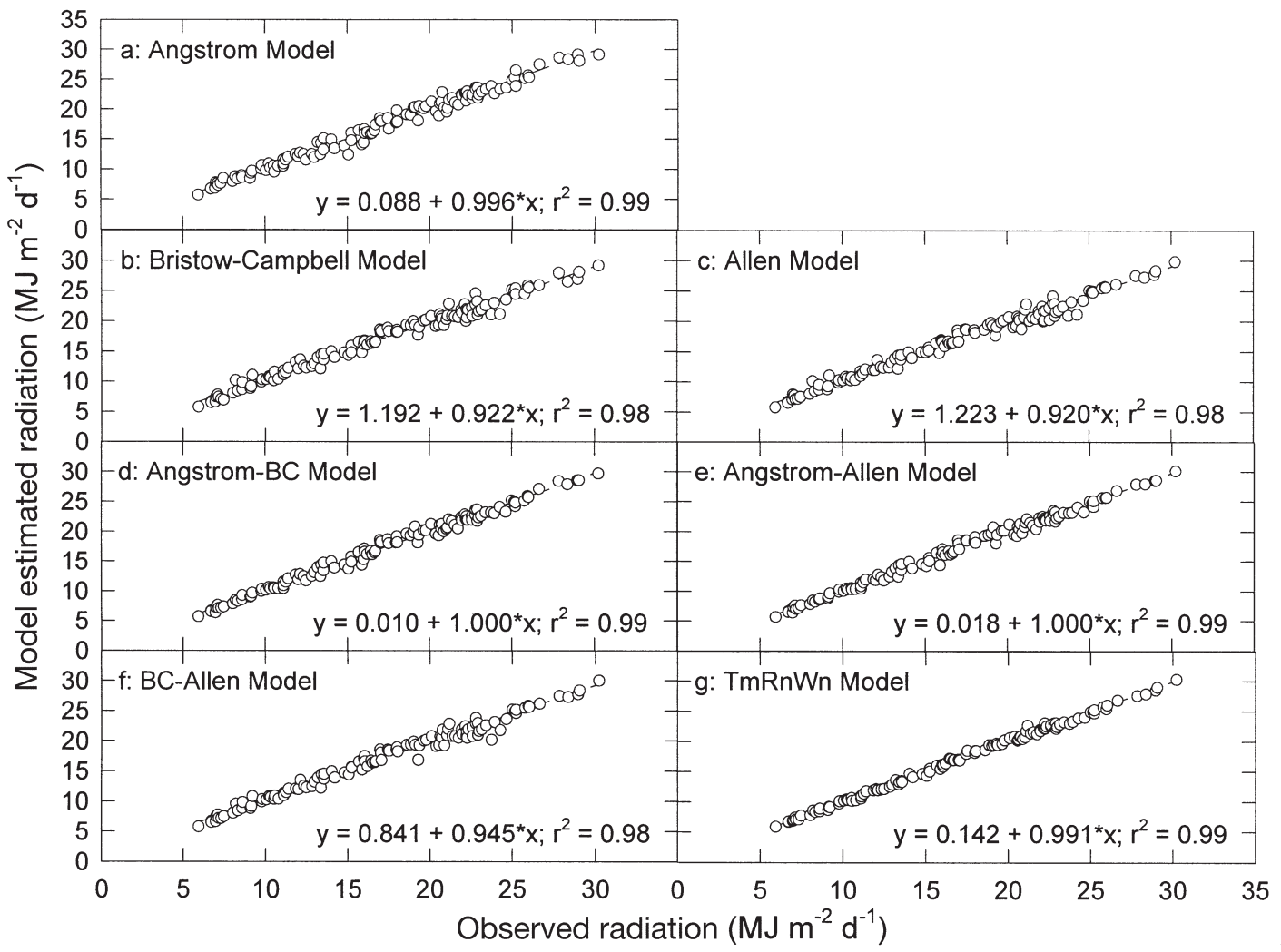

Fig. 3. Regression plots of model estimated versus observed solar radiation across 10 locations, for 7 solar radiation models and Scheme 4 (monthly and interannual averaging) 
monthly mean $I_{\text {rad }}$ ). Effects of monthly averaging only (Scheme 2) and interannual averaging only (Scheme 3) the single TASs are reflected in $\mathrm{r}^{2}$ values and ranges intermediate between Scheme 1 (no temporal averaging) and Scheme 4 (monthly-plus-interannual averaging) (Table 3). Slightly higher $\mathrm{r}^{2}$ for Scheme 2 compared to Scheme 3 reflect slightly greater temporal smoothing achieved via monthly averaging compared to interannual averaging.

For the geographical composite, LCS was the major statistical source of variation $(>80 \%)$ between predicted and measured solar radiation for all 28 scenarios, with minor contributions from SDSD $(<20 \%)$ and SB $(<2 \%)$ (Table 3$)$. Sources of variation between $I_{\text {rad }}$ estimations and measurements were in the order LCS > SDSD $>$ SB. Relative ratios depended on SRM and TAS. For example, for the TmRnWn model, LCS contributions ranged from $86.1 \%$ (Scheme 1) to $99.3 \%$ (Scheme 4). Among the 7 SRMs, LCS contributions were greater (and SDSD contributions correspondingly less) for Schemes 2, 3, and 4 than for Scheme 1, whereas SB contributions were constant and insignificant across the 28 scenarios. The SDSD results illustrate the effect of temporal averaging in smoothing out (reducing) fluctuations between predicted and measured solar radiations, thus enhancing the scenario's ability to simulate the fluctuation magnitude. MSV and MSD were greatest for Scheme 1 (ranging from 22 to 26), intermediate for Schemes 2 and 3 (2.5 to 3.8), and smallest for Scheme 4 (0.23 to 1.06), showing the temporal averaging effect of reducing variance and deviations between predicted and measured solar radiations.

Temporal averaging over one or more time scales (i.e. monthly, interannual) smooths out shorter-term fluctuations, resulting in decreased temporal scatter in weather parameters. In absence of temporal averaging, extreme-weather days may exist in the historical data, and daily $I_{\text {rad }}$ and other weather parameters are more difficult to predict on extreme-weather days (resulting in high data scatter and low $\mathrm{r}^{2}$ ). Temporal averaging suppresses anomalous extreme-weather days by averaging them with normal days, generating a smoother, more predictable temporal profile. A smooth temporal profile is easier to predict, resulting in low data scatter and high $\mathrm{r}^{2}$. Daily weather parameters (Scheme 1) exhibit greater scatter (due to extremeweather days) than monthly means (Scheme 2), and interannual averaging of daily parameters (Scheme 3) smoothes out anomalous extreme-weather days in isolated years (Scheme 1). Two-step temporal averaging (Scheme 4) smoothes out the weather profile further by averaging extreme-weather events of longer duration, resulting in additional reductions in temporal scatter.

3.2.2. Comparison among solar radiation models and locations. The TmRnWn and Angstrom models exhibited the highest and lowest $r^{2}$, respectively (Table 3). Apparently TmRnWn was the most accurate in predicting $I_{\text {rad }}$, compared to the other 6 SRMs. The TmRnWn model incorporates a greater number of adjustable parameters $\left(a_{0}, a_{1}, a_{2}, a_{3}, a_{4}\right.$ Eq. 4$)$ in its algorithm compared to the other 6 SRMs. The Angstrom model contains only 1 adjustable parameter, which probably explains its relatively low performance. The Bristow-Campbell and Allen models each contain 2 adjustable parameters, and the 3 hybrid models contain either 2 (BC-Allen) or 3 (Angstrom-BC, Angstrom-Allen) adjustable parameters. As the number of adjustable parameters in a model's algorithm increases, model flexibility and degrees of freedom increase, and hence model performance is expected to increase, assuming physically realistic fundamental model principles.

For a given SRM and TAS, $I_{\text {rad }}$ estimations were most accurate (i.e. highest $r^{2}$ ) for Shafter, followed by Maricopa (data not shown). For Shafter and Maricopa (as with the geographical composite; Table 3$), r^{2}$ values among the 7 SRMs were highest for Scheme 4 and lowest for Scheme 1, showing temporal averaging effects in reducing temporal variability in $I_{\text {rad }}$. These 2 arid locations (Shafter and Maricopa) exhibit high air temperatures, low precipitation, a large annual number of sunny days, and hence highly predictable weather, particularly in regard to $I_{\text {rad }}$. Such high predictability as affected by climate and geography renders $I_{\text {rad }}$ estimations relatively more accurate .

For a given SRM and TAS, the geographical composite $r^{2}$ was intermediate among the $r^{2}$ values for the 10 locations (Table 3). For the TmRnWn model and Scheme 1, the geographical composite $\mathrm{r}^{2}$ was 0.652 (Table 3), whereas $\mathrm{r}^{2}$ ranged from 0.594 (Portageville) to 0.908 (Shafter) among the 10 locations (data not shown). Similar trends were observed for the other SRMs and TASs (Table 3). Scatter of location-specific $\mathrm{r}^{2}$ values about the geographical composite $r^{2}$ reflect geographical variability in $I_{\text {rad }}$, which in turn illustrates effects of geography and associated changes in regional climate on measured $I_{\text {rad }}$ and on $I_{\text {rad }}$ estimation accuracy. Each SRM was empirically parameterized, calibrated, and evaluated with experimental data covering a wide range of environmental parameters typically encountered under field conditions. While each SRM was sufficiently evaluated to be applied to all 10 locations, these locations exhibited different ranges of environmental parameters that depend on associated regional climate differences. Typical daily air temperature ranges in northern locations (Portageville and Springfield) are different (i.e. centered toward lower temperatures) compared to southern locations.

Some SRMs do not parameterize any additional weather parameters beyond daylength, $T_{\min }$ and $T_{\max }$ 
in their algorithms describing $I_{\text {rad }}$. In addition to daylength, $T_{\min }$ and $T_{\max }$ other parameters potentially correlating with $I_{\text {rad }}$ include PPT and WIND (both of which are included along with $T_{\min }$ and $T_{\max }$ in the TmRnWn model), as well as humidity. These weather parameters exhibit geographical variability (e.g. lower PPT in the arid Southwest than in the humid Southeast; negative correlation between air temperature and latitude), which contributes to geographical variability in measured $I_{\text {rad }}$ and in predicted $I_{\text {rad }}$ for a given SRM and TAS. A given SRM and TAS may thus predict $I_{\text {rad }}$ with high accuracy when applied to individual locations (as reflected in high $\mathrm{r}^{2}$ in the regression plot of $I_{\text {rad,pred }}$ versus $I_{\text {rad,meas }}$ ), but differences in $I_{\text {rad }}$ behavior between locations (due to climatic differences) may contribute to geographical scatter (reduced $\mathrm{r}^{2}$ ) when the $I_{\text {rad,pred }}$ versus $I_{\text {rad,meas }}$ data from different locations (covering a wide range of geography and climate) are included on the same regression plot (geographical composite).

3.2.3. Best solar radiation estimations. Comparing all 4 TASs, 7 SRMs, and 10 locations, the best performance in predicting $I_{\text {rad }}$ was obtained with the TmRnWn model using Scheme 4 in Maricopa $\left(r^{2}=0.999\right)$. Geographical composite $\mathrm{r}^{2}$ values for the 28 scenarios, with an indication of the best and worst SRM in predicting solar radiation for each of the 4 TASs, are given in Table 4 . Among the 7 SRMs, the TmRnWn model performed the best in all 4 TASs $\left(r^{2}=0.652,0.936,0.937,0.994\right)$ (Table 4). The combination of an accurate, reliable, realistic, highly parameterized SRM, a double TAS to smooth out short-term temporal fluctuations in $I_{\text {rad }}$ (Scheme 4), and an arid location with high air temperatures, low precipitation, a large annual number of sunny days, and highly predictable weather (Maricopa) contributed to high $I_{\text {rad }}$ estimation accuracy. Integrated across all 10 locations, the most accurate $I_{\text {rad }}$ estimations were obtained with the TmRnWn-Scheme 4 scenario (composite $\mathrm{r}^{2}=0.994$; Table 4).

Similar studies on Angstrom, Bristow-Campbell, and Allen model predictions of $I_{\text {rad, }}$ using different TASs, were conducted by other researchers (Angstrom 1924, Bristow \& Campbell 1984, Allen 1995, 1997, Meza \& Varas 2001), who observed geographical variability in the SRMs' empirical coefficients as well as variable performances among the SRMs depending on TAS and temperature range $\left(T_{\max }-T_{\min }\right)$. However, these studies did not address the further applicability of these SRMs in predicting crop yields when coupled to CSMs. This study explores this additional application with the aid of GOSSYM, as discussed in the following section.

\subsection{Cotton yield estimations}

Linear regression coefficients $\left(b_{0}, b_{1}, \mathrm{r}^{2}\right)$ from plots of $Y_{\text {sim,pred }}$ versus $Y_{\text {sim,meas }}$ were calculated for the 7 SRMs, 4 TASs, 10 locations, and the geographical composite. The MSV, MSD, and the SB/MSD, SDSD/MSD, and LCS/MSD ratios were also calculated. For the sake of brevity, only the geographical composite results for the 28 scenarios are summarized in Table 5a and 5b. The 
coefficients are summarized for $\mathrm{RF}$, IRR, and both $\mathrm{RF}$ and IRR (RF + IRR) cotton yields. Geographical composite regression plots for the $7 \mathrm{SRMs}$ are shown in Figs. 4, 5, 6, \& 7 for Schemes 1, 2, 3, and 4, respectively. Analogous plots for the 10 individual locations were omitted for clarity. In each of the regression plots, 2 linear regression lines were drawn, representing $\mathrm{RF}$ and IRR data. Accuracy of yield estimations depended on TAS, management practice (RF, IRR), SRM, and location.

3.3.1. Temporal-averaging effects: Yield and $I_{\text {rad }}$ estimation comparisons. Among the 4 TASs, 7 SRMs, and 10 locations, estimation accuracies were higher for RF and IRR yields than for $I_{\text {rad, }}$ particularly for Scheme 1 , which showed the lowest $I_{\text {rad }}$ estimation accuracy among the 4 TASs. For example, for the TmRnWn model, geographical composite $r^{2}=0.933,0.827$, and
0.948 for predicting $R F$, IRR, and RF + IRR yields (Table 5a), compared to 0.652 for predicting $I_{\text {rad }}$ (Table 3).

For the geographical composite, LCS was the major statistical source of variation ( $>65 \%$ ) between predicted and measured RF/IRR yields for all 28 scenarios, with minor contributions from SB $(<34 \%)$ and SDSD $(<4 \%)$ (Table $5 \mathrm{~b})$. Sources of variation between yield estimations and measurements were in the order LCS $>\mathrm{SB}>\mathrm{SDSD}$ (compared to the order LCS > SDSD > SB for $I_{\text {rad }}$ estimations and measurements; Table 3). Relative ratios depended on SRM, TAS, and management practice (RF, IRR). For the TmRnWn model, LCS contributions ranged from $77.6 \%$ (Scheme 3) to $93.4 \%$ (Scheme 1) for RF yield, and ranged from 69.5\% (Scheme 4) to $98.7 \%$ (Scheme 1) for IRR yield. For a given scenario, LCS contributions were greater (and

Table 5a. Linear (LSRA) regression coefficients and determination coefficients $\left(\mathrm{r}^{2}\right)$ for simulated cotton yields using predicted versus measured solar radiation, for the given solar radiation model and temporal-averaging scheme, for the geographical composite. Daily predicted solar radiations were calculated from algorithms describing daily solar radiation for each year $\left(y=a_{\mathrm{o}}+a_{1} \cdot x_{1}\right)$ (137 data points). LSRA: $y=a_{\mathrm{o}}+a_{1} \cdot x_{1}$, where $y=$ simulated yield $\left(\mathrm{kg} \mathrm{ha}^{-1}\right)$ using solar radiation predicted by the given solar radiation model and $x_{1}=$ simulated yield $\left(\mathrm{kg} \mathrm{ha}^{-1}\right)$ using measured solar radiation

\begin{tabular}{|c|c|c|c|c|c|c|c|c|c|}
\hline \multirow{2}{*}{$\begin{array}{l}\text { Solar radiation } \\
\text { model }\end{array}$} & \multicolumn{3}{|c|}{ Rainfed } & \multicolumn{3}{|c|}{ Irrigated } & \multicolumn{3}{|c|}{ Rainfed + Irrigated } \\
\hline & $a_{\mathrm{o}}$ & $a_{1}$ & $r^{2}$ & $a_{0}$ & $a_{1}$ & $r^{2}$ & $a_{\mathrm{o}}$ & $a_{1}$ & $\mathrm{r}^{2}$ \\
\hline \multicolumn{10}{|l|}{ Scheme 1} \\
\hline Angstrom & 81 & 1.005 & 0.931 & 281 & 0.898 & 0.816 & 106 & 0.983 & 0.947 \\
\hline Bristow-Campbell & 29 & 0.985 & 0.943 & 89 & 0.987 & 0.863 & 11 & 1.017 & 0.959 \\
\hline Allen & 94 & 0.974 & 0.926 & 130 & 0.945 & 0.856 & 106 & 0.959 & 0.948 \\
\hline Angstrom-BC & 39 & 0.986 & 0.950 & 145 & 0.950 & 0.862 & 36 & 0.998 & 0.962 \\
\hline Angstrom-Allen & 79 & 0.975 & 0.934 & 200 & 0.912 & 0.869 & 93 & 0.963 & 0.954 \\
\hline BC-Allen & 57 & 0.977 & 0.941 & 109 & 0.965 & 0.873 & 51 & 0.989 & 0.959 \\
\hline TmRnWn & 79 & 0.969 & 0.933 & 107 & 0.951 & 0.827 & 85 & 0.963 & 0.948 \\
\hline \multicolumn{10}{|l|}{ Scheme 2} \\
\hline Angstrom & 78 & 1.018 & 0.936 & 260 & 0.910 & 0.813 & 109 & 0.986 & 0.947 \\
\hline Bristow-Campbell & 127 & 0.982 & 0.931 & 179 & 0.935 & 0.845 & 148 & 0.954 & 0.948 \\
\hline Allen & 119 & 0.997 & 0.917 & 193 & 0.923 & 0.839 & 155 & 0.950 & 0.938 \\
\hline Angstrom-BC & 72 & 1.003 & 0.939 & 221 & 0.922 & 0.831 & 93 & 0.984 & 0.952 \\
\hline Angstrom-Allen & 71 & 1.014 & 0.933 & 269 & 0.894 & 0.836 & 106 & 0.977 & 0.949 \\
\hline BC-Allen & 112 & 1.000 & 0.924 & 190 & 0.927 & 0.836 & 146 & 0.956 & 0.942 \\
\hline TmRnWn & 51 & 1.015 & 0.933 & 270 & 0.900 & 0.823 & 77 & 0.993 & 0.949 \\
\hline \multicolumn{10}{|l|}{ Scheme 3} \\
\hline Angstrom & 81 & 1.005 & 0.931 & 281 & 0.898 & 0.816 & 106 & 0.983 & 0.947 \\
\hline Bristow-Campbell & 127 & 0.986 & 0.926 & 223 & 0.915 & 0.814 & 155 & 0.953 & 0.941 \\
\hline Allen & 133 & 0.993 & 0.911 & 261 & 0.893 & 0.802 & 174 & 0.943 & 0.930 \\
\hline Angstrom-BC & 95 & 1.006 & 0.929 & 282 & 0.895 & 0.811 & 127 & 0.973 & 0.944 \\
\hline Angstrom-Allen & 107 & 1.004 & 0.918 & 288 & 0.886 & 0.800 & 146 & 0.961 & 0.935 \\
\hline BC-Allen & 126 & 0.998 & 0.920 & 268 & 0.890 & 0.802 & 169 & 0.946 & 0.935 \\
\hline TmRnWn & 75 & 1.012 & 0.929 & 300 & 0.891 & 0.792 & 104 & 0.986 & 0.943 \\
\hline \multicolumn{10}{|l|}{ Scheme 4} \\
\hline Angstrom & 78 & 1.018 & 0.936 & 260 & 0.910 & 0.813 & 109 & 0.986 & 0.947 \\
\hline Bristow-Campbell & 136 & 0.995 & 0.923 & 230 & 0.911 & 0.823 & 174 & 0.946 & 0.939 \\
\hline Allen & 111 & 1.011 & 0.915 & 249 & 0.903 & 0.814 & 156 & 0.956 & 0.933 \\
\hline Angstrom-BC & 90 & 1.013 & 0.931 & 239 & 0.918 & 0.795 & 120 & 0.980 & 0.942 \\
\hline Angstrom-Allen & 86 & 1.017 & 0.931 & 249 & 0.913 & 0.806 & 120 & 0.980 & 0.943 \\
\hline BC-Allen & 113 & 1.011 & 0.914 & 238 & 0.913 & 0.809 & 152 & 0.963 & 0.933 \\
\hline TmRnWn & 62 & 1.019 & 0.929 & 270 & 0.916 & 0.811 & 82 & 1.005 & 0.946 \\
\hline
\end{tabular}


Table 5b. Mean square variance and deviation coefficients (MSV, MSD, SB, SDSD, LCS) for simulated cotton yields using predicted versus measured solar radiation, for the given solar radiation model and temporal-averaging scheme, for the geographical composite. Daily predicted solar radiations were calculated from algorithms describing daily solar radiation for each year (137 data points). $Y=$ simulated yield $\left(\mathrm{kg} \mathrm{ha}^{-1}\right)$ using solar radiation predicted by the given solar radiation model and $x_{1}=$ simulated yield $\left(\mathrm{kg} \mathrm{ha}^{-1}\right)$ using measured solar radiation

\begin{tabular}{|c|c|c|c|c|c|c|c|c|c|c|c|c|c|c|c|}
\hline \multirow{2}{*}{$\begin{array}{l}\text { Solar radiation } \\
\text { model }\end{array}$} & \multicolumn{5}{|c|}{ Rainfed } & \multicolumn{5}{|c|}{ Irrigated } & \multicolumn{5}{|c|}{ Rainfed + Irrigated } \\
\hline & MSV & MSD & $\begin{array}{l}\text { SB/ } \\
\text { MSD }\end{array}$ & $\begin{array}{l}\text { SDSD/ } \\
\text { MSD }\end{array}$ & $\begin{array}{l}\text { LCS/ } \\
\text { MSD }\end{array}$ & MSV & MSD & $\begin{array}{l}\text { SB/ } \\
\text { MSD }\end{array}$ & $\begin{array}{l}\text { SDSD/ } \\
\text { MSD }\end{array}$ & $\begin{array}{l}\text { LCS/ } \\
\text { MSD }\end{array}$ & MSV & MSD & $\begin{array}{l}\text { SB/ } \\
\text { MSD }\end{array}$ & $\begin{array}{l}\text { SDSD/ } \\
\text { MSD }\end{array}$ & $\begin{array}{l}\text { LCS } \\
\text { MSD }\end{array}$ \\
\hline \multicolumn{16}{|l|}{ Scheme 1} \\
\hline Angstrom & 30307 & 27872 & 0.200 & 0.019 & 0.782 & 20725 & 25863 & 0.199 & 0.000 & 0.801 & 25574 & 31867 & 0.197 & 0.002 & 0.801 \\
\hline Bristow-Campbell & 24127 & 24281 & 0.006 & 0.004 & 0.990 & 16641 & 20518 & 0.189 & 0.020 & 0.791 & 21006 & 22399 & 0.062 & 0.031 & 0.907 \\
\hline Allen & 30954 & 35099 & 0.118 & 0.002 & 0.880 & 16514 & 16827 & 0.019 & 0.003 & 0.978 & 24279 & 25963 & 0.065 & 0.004 & 0.931 \\
\hline Angstrom-BC & 21024 & 21570 & 0.025 & 0.003 & 0.972 & 15758 & 17616 & 0.105 & 0.003 & 0.891 & 18488 & 19593 & 0.056 & 0.007 & 0.936 \\
\hline Angstrom-Allen & 27811 & 30327 & 0.083 & 0.001 & 0.916 & 14361 & 14707 & 0.024 & 0.003 & 0.973 & 21335 & 22517 & 0.053 & 0.004 & 0.943 \\
\hline BC-Allen & 24514 & 25401 & 0.035 & 0.001 & 0.964 & 14667 & 16031 & 0.085 & 0.007 & 0.908 & 19603 & 20716 & 0.054 & 0.002 & 0.944 \\
\hline TmRnWn & 27672 & 29609 & 0.065 & 0.000 & 0.934 & 20640 & 20680 & 0.002 & 0.011 & 0.987 & 24510 & 25144 & 0.025 & 0.002 & 0.972 \\
\hline \multicolumn{16}{|l|}{ Scheme 2} \\
\hline Angstrom & 28951 & 38545 & 0.249 & 0.029 & 0.723 & 21330 & 26862 & 0.206 & 0.000 & 0.794 & 25279 & 32703 & 0.227 & 0.002 & 0.771 \\
\hline Bristow-Campbell & 29161 & 40476 & 0.280 & 0.003 & 0.717 & 17646 & 19637 & 0.101 & 0.002 & 0.897 & 24356 & 30057 & 0.190 & 0.006 & 0.804 \\
\hline Allen & 36492 & 49867 & 0.268 & 0.014 & 0.718 & 18244 & 19426 & 0.061 & 0.000 & 0.939 & 29020 & 34646 & 0.162 & 0.005 & 0.833 \\
\hline Angstrom-BC & 26722 & 32506 & 0.178 & 0.016 & 0.806 & 19262 & 22807 & 0.155 & 0.001 & 0.844 & 23060 & 27656 & 0.166 & 0.001 & 0.832 \\
\hline Angstrom-Allen & 30130 & 37590 & 0.198 & 0.026 & 0.775 & 18013 & 20675 & 0.129 & 0.003 & 0.869 & 24374 & 29132 & 0.163 & 0.000 & 0.837 \\
\hline BC-Allen & 33337 & 45940 & 0.274 & 0.014 & 0.711 & 18687 & 20242 & 0.077 & 0.001 & 0.922 & 27337 & 33091 & 0.174 & 0.003 & 0.823 \\
\hline TmRnWn & 30118 & 34670 & 0.131 & 0.030 & 0.839 & 19826 & 23935 & 0.172 & 0.000 & 0.828 & 24975 & 29303 & 0.148 & 0.006 & 0.846 \\
\hline \multicolumn{16}{|l|}{ Scheme 3} \\
\hline Angstrom & 30307 & 37872 & 0.200 & 0.019 & 0.782 & 20725 & 25863 & 0.199 & 0.000 & 0.801 & 25574 & 31867 & 0.197 & 0.002 & 0.801 \\
\hline Bristow-Campbell & 31731 & 44099 & 0.280 & 0.006 & 0.714 & 21287 & 23555 & 0.096 & 0.001 & 0.903 & 27520 & 33827 & 0.186 & 0.004 & $0.80 \mathrm{~s}$ \\
\hline Allen & 39146 & 54897 & 0.287 & 0.012 & 0.701 & 22387 & 24079 & 0.070 & 0.000 & 0.930 & 32546 & 39488 & 0.176 & 0.006 & 0.818 \\
\hline Angstrom-BC & 31503 & 41831 & 0.247 & 0.018 & 0.735 & 21257 & 25563 & 0.168 & 0.000 & 0.831 & 26704 & 33697 & 0.208 & 0.000 & 0.792 \\
\hline Angstrom-Allen & 36857 & 49298 & 0.252 & 0.019 & 0.728 & 22470 & 25403 & 0.115 & 0.000 & 0.884 & 30486 & 37351 & 0.184 & 0.001 & 0.816 \\
\hline BC-Allen & 35224 & 50400 & 0.301 & 0.013 & 0.686 & 22319 & 23958 & 0.068 & 0.000 & 0.931 & 30482 & 37179 & 0.180 & 0.006 & 0.814 \\
\hline TmRnWn & 31715 & 39610 & 0.199 & 0.025 & 0.776 & 23722 & 29496 & 0.196 & 0.000 & 0.804 & 27760 & 34553 & 0.197 & 0.003 & 0.800 \\
\hline \multicolumn{16}{|l|}{ Scheme 4} \\
\hline Angstrom & 28951 & 38545 & 0.249 & 0.029 & 0.723 & 21330 & 26862 & 0.206 & 0.000 & 0.794 & 25279 & 32703 & 0.227 & 0.002 & 0.771 \\
\hline Bristow-Campbell & 33872 & 50873 & 0.334 & 0.010 & 0.655 & 20000 & 22140 & 0.097 & 0.000 & 0.903 & 28705 & 36507 & 0.214 & 0.007 & 0.770 \\
\hline Allen & 38902 & 54333 & 0.284 & 0.025 & 0.691 & 21094 & 23417 & 0.099 & 0.000 & 0.901 & 31443 & 38875 & 0.191 & 0.001 & 0.808 \\
\hline Angstrom-BC & 31269 & 42295 & 0.261 & 0.025 & 0.715 & 24136 & 29212 & 0.174 & 0.003 & 0.823 & 27988 & 35754 & 0.217 & 0.001 & 0.782 \\
\hline Angstrom-Allen & 31456 & 42666 & 0.263 & 0.028 & 0.709 & 22441 & 27423 & 0.182 & 0.001 & 0.817 & 27260 & 35044 & 0.222 & 0.001 & 0.777 \\
\hline BC-Allen & 39029 & 54751 & 0.287 & 0.024 & 0.688 & 21986 & 25536 & 0.139 & 0.001 & 0.860 & 31590 & 40143 & 0.213 & 0.000 & 0.787 \\
\hline TmRnWn & 32413 & 39483 & 0.179 & 0.034 & 0.787 & 21737 & 31246 & 0.304 & 0.001 & 0.695 & 27120 & 35364 & 0.233 & 0.015 & 0.752 \\
\hline
\end{tabular}

SB contributions were correspondingly less) for IRR than for RF yields, whereas SDSD contributions were constant and insignificant between RF and IRR yields.

Differences in geographical composite estimation accuracies between yield and $I_{\text {rad }}$ were less significant for Schemes 2, 3, and 4 than for Scheme 1, with accuracy differences between yield and $I_{\text {rad }}$ estimations depending on SRM and management practice. For the TmRnWn-Scheme 4 scenario, geographical composite $\mathrm{r}^{2}$ was $0.929,0.811$, and 0.946 for predicting the 3 types of yields (Table 5a), compared to 0.994 for predicting $I_{\text {rad }}$ (Table 3$)$, showing that this scenario predicted $I_{\text {rad }}$ better than the yields. Thus, temporal averaging appears to improve the accuracy of a given SRM's $I_{\text {rad }}$ estimations relative to yield estimations.

Yield estimation accuracy depended on location and management practice and was relatively insensitive to TAS and SRM, as shown by relatively constant $r^{2}$ among the 4 TASs (Table 5a). The following generalizations can be drawn regarding effects of temporal averaging on $I_{\text {rad }}$ and yield estimation accuracies: (1) estimation accuracy was higher for yield than for $I_{\text {rad }}$ among the TASs, SRMs, and locations; (2) temporal averaging significantly improved $I_{\text {rad }}$ estimation accuracy (Table 3); (3) temporal averaging had a negligible effect on yield estimation accuracy (Table 5a); (4) temporal averaging decreased the difference in estimation accuracies between yield and $I_{\text {rad }}$.

As discussed earlier, a source of low $I_{\text {rad }}$ estimation accuracy was high temporal variability in daily weather parameters. Scatter reduction via temporal averaging over monthly and/or interannual time scales improved $I_{\mathrm{rad}}$ estimation accuracy, as shown by comparing $\mathrm{r}^{2}$ values among the 4 TASs (Table 3 ). Apparently the propagation of a given accuracy in $I_{\text {rad }}$ estimations (via substituting $I_{\text {rad,meas }}$ with $I_{\text {rad,pred }}$ to drive GOSSYM) to generate yield estimations smoothes out adverse effects of high temporal variability in daily weather parameters (which generated low $I_{\text {rad }}$ estimation accuracies), resulting in improved yield estimations over $I_{\text {rad }}$ estimations 


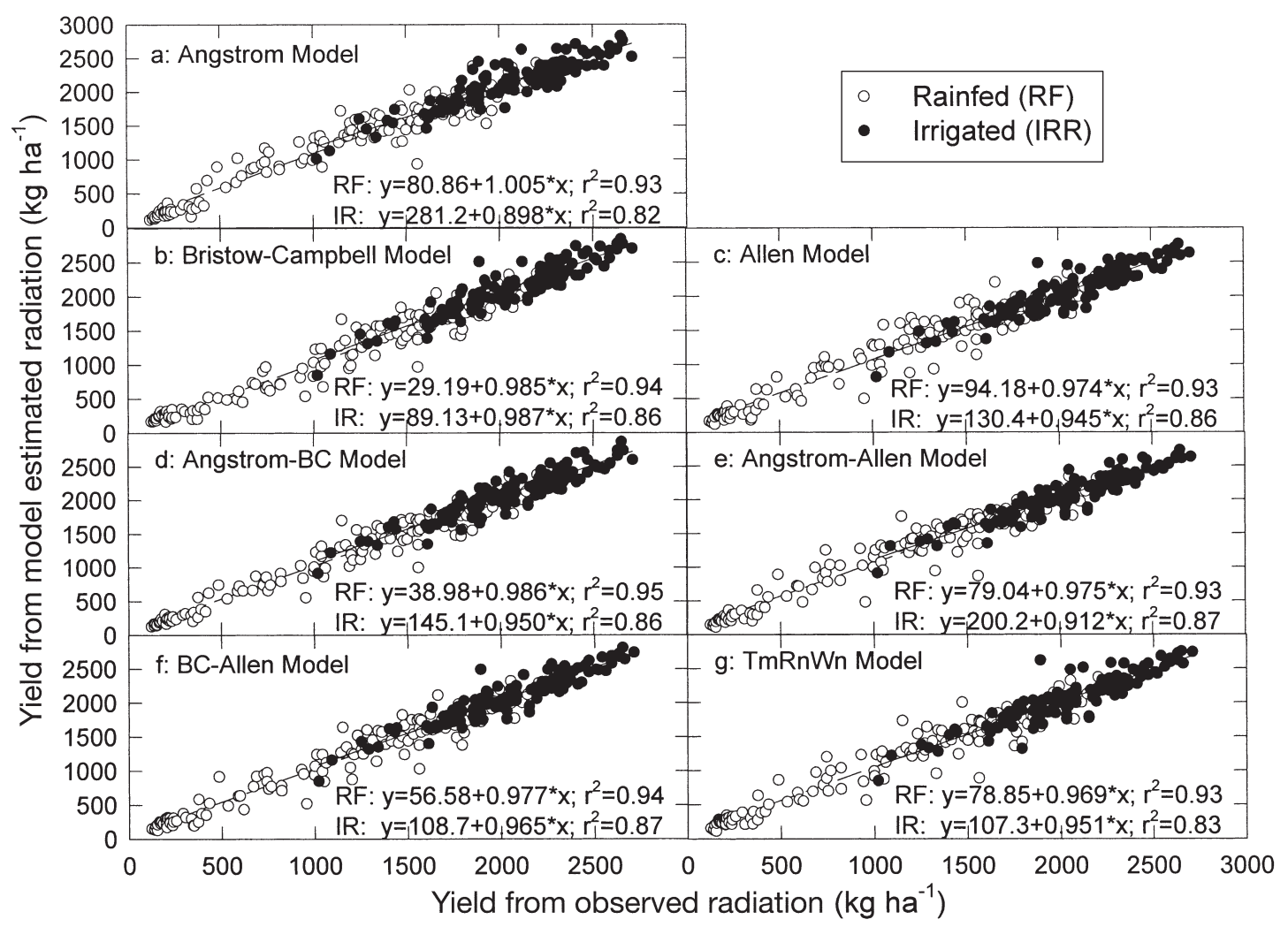

Fig. 4. Regression plots of simulated cotton yields driven by model estimated versus observed solar radiation across 10 locations, for 7 solar radiation models and Scheme 1 (no temporal averaging)

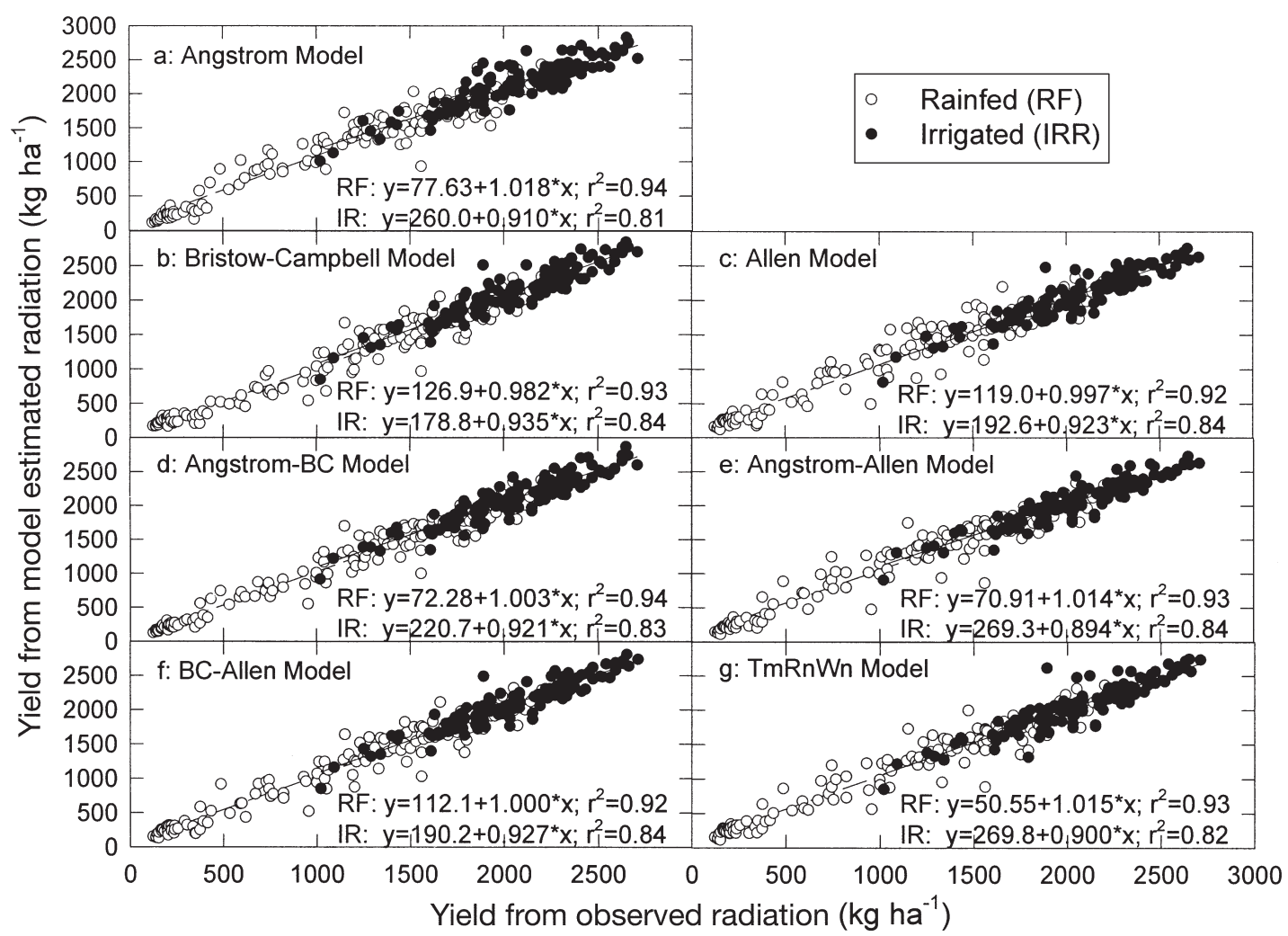

Fig. 5. Regression plots of simulated cotton yields driven by model estimated versus observed solar radiation across 10 locations, for 7 solar radiation models and Scheme 2 (monthly averaging) 


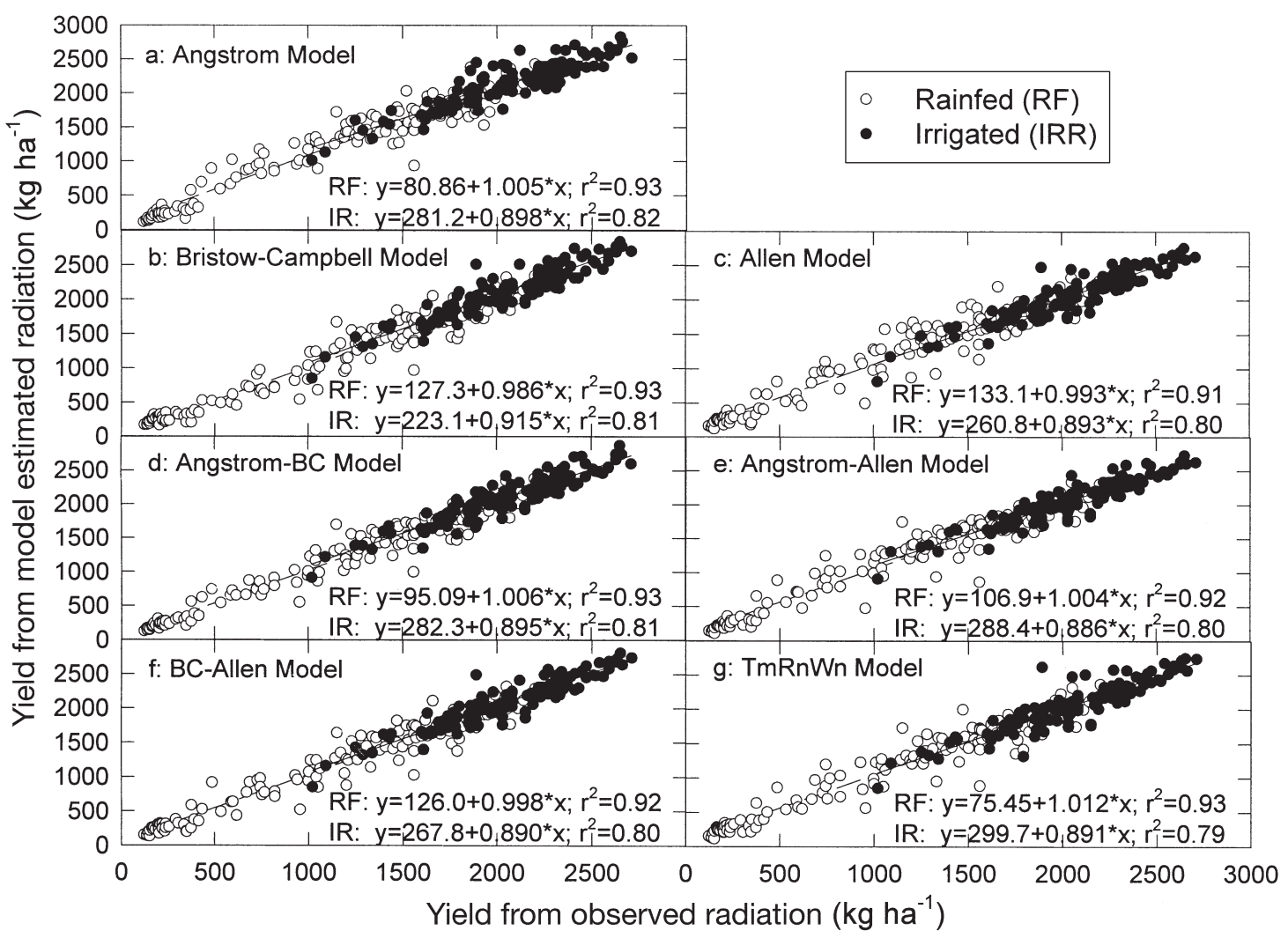

Fig. 6. Regression plots of simulated cotton yields driven by model estimated versus observed solar radiation across 10 locations, for 7 solar radiation models and Scheme 3 (interannual averaging)

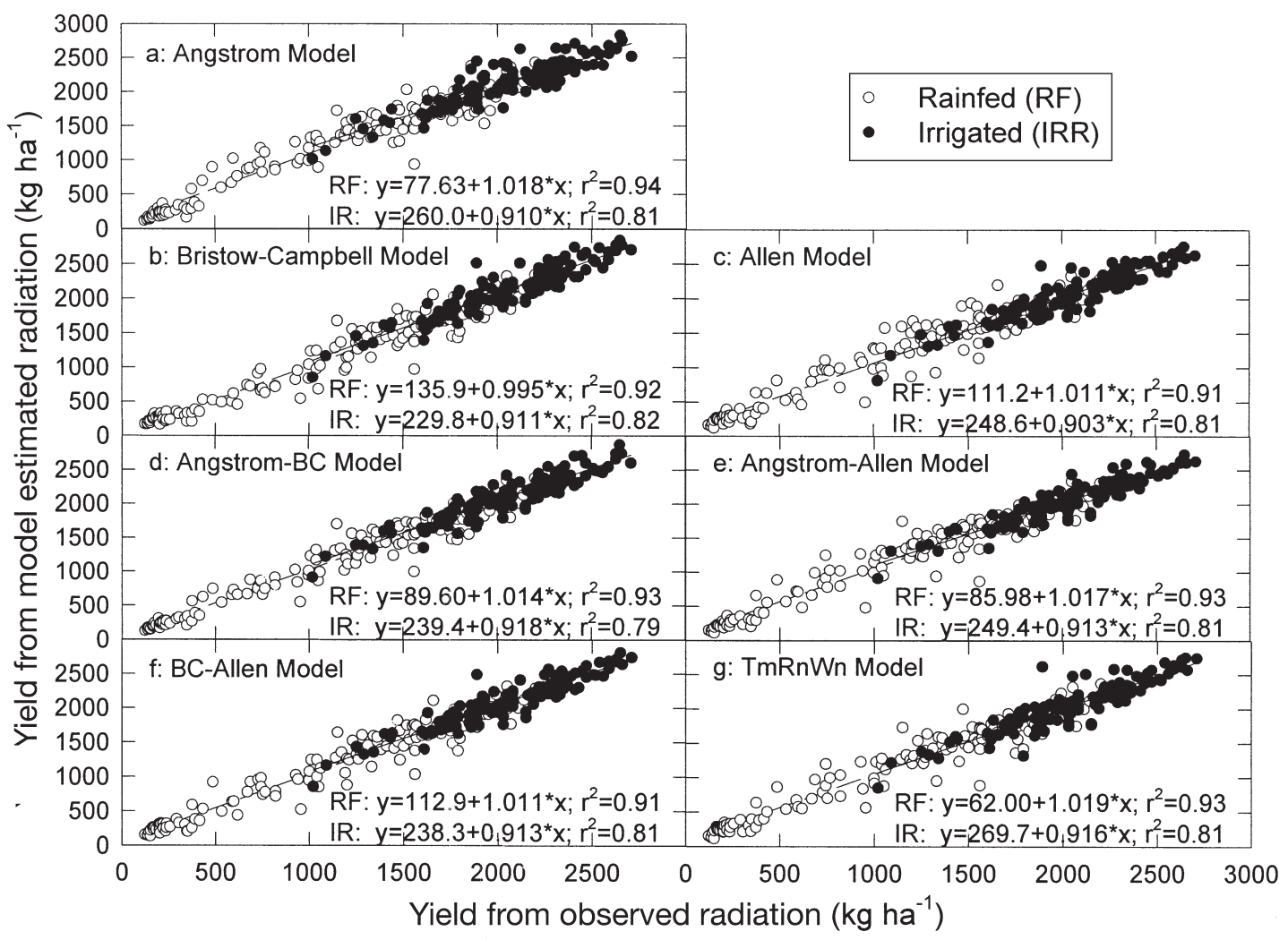

Fig. 7. Regression plots of simulated cotton yields driven by model estimated versus observed solar radiation across 10 locations, for 7 solar radiation models and Scheme 4 (monthly and interannual averaging) 
(Scheme 1). However, if $I_{\text {rad }}$ variability was previously smoothed out by temporal averaging (to generate improved $I_{\text {rad }}$ estimation accuracies), propagation resulted in smaller and/or negligible improvements in accuracy of yield estimations over $I_{\text {rad }}$ estimations (Schemes 2 to 4). Thus, temporal averaging of daily weather parameters improves $I_{\text {rad }}$ estimations significantly but yield estimations only negligibly.

The extent of the smoothing (dilution) effect brought about by propagating $I_{\text {rad }}$ estimation accuracy to generate yield estimations via GOSSYM depends on yield response to changes in $I_{\text {rad }}$ and other environmental parameters. One contributing factor is the fact that numerous other parameters besides $I_{\text {rad }}$ (e.g. other weather parameters, management, soil, and cultivar properties) affect yield. These other factors were held constant in the GOSSYM simulations while only the $I_{\text {rad }}$ input datasets were varied between $I_{\text {rad,meas }}$ and $I_{\text {rad,pred. }}$ In addition, while some of the physiological processes affecting yield depend on $I_{\text {rad }}$ (e.g. photosynthesis [PNS], evapotranspiration [ET]), other physiological growth and development processes (e.g. root growth and development, phenology, leaf initiation, stem elongation) affecting yield are independent of $I_{\text {rad. }}$. Under conditions where these light-independent processes significantly affect yield, such that yield is relatively less sensitive to light-dependent processes, yield response to changes in $I_{\text {rad }}$ is expected to be relatively small. As yield sensitivity to changes in lightdependent processes (relative to light-independent processes) increases, yield is expected to become more sensitive to changes in $I_{\text {rad. }}$.

GOSSYM's parameterization of light-dependent processes exhibits sensitivities to changes in $I_{\text {rad }}$ that depend on $I_{\text {rad }}$ level. PNS shows a positive hyperbolic response to increases in $I_{\text {rad }}$ and ET (atmospheric evaporative demand AED) correlates positively and linearly with $I_{\text {rad. }}$. These 2 physiological processes exhibit opposing effects on yield, with PNS being beneficial via enhanced carbon supply and fixation, and AED/ET being adverse via drought stress exacerbation. Their net effect on yield depends on their relative magnitudes, which in turn depend on $I_{\text {rad }}$ level and management practice. As $I_{\text {rad }}$ increases, yield can increase or decrease, depending on $I_{\text {rad }}$ level. At low $I_{\text {rad, }}$ PNS is relatively sensitive to $I_{\text {rad }}$ and usually more sensitive than ET, hence the beneficial effect > adverse effect, resulting in a positive yield- $I_{\text {rad }}$ correlation. In contrast, at high $I_{\text {rad, }}$ PNS is relatively insensitive to $I_{\text {rad }}$ compared to ET, hence the adverse effect $>$ beneficial effect, resulting in a negative yield- $I_{\text {rad }}$ correlation. At moderate $I_{\text {rad }}$ (depending on management practice), the beneficial and adverse effects are approximately balanced, resulting in a negligible yield response to changes in $I_{\text {rad. }}$.
These cases are particularly valid under RF (drought stress) conditions. However, under IRR (alleviated drought stress) conditions, the adverse AED/ET effect on yield reduction is suppressed. Thus, yield response to changes in $I_{\text {rad }}$ is more closely correlated with PNS response under IRR conditions than under RF conditions. Interaction effects exist between $I_{\text {rad }}$ and drought stress, such that yield response to $I_{\text {rad }}$ differs between optimal (IRR) and drought-stress (RF) conditions. Under IRR conditions, yield correlates positively with $I_{\text {rad }}$ over the entire range of $I_{\text {rad, }}$ whereas under RF conditions, yield correlates positively with $I_{\text {rad }}$ at low $I_{\text {rad }}$ (due to the beneficial PNS effect predominating over the adverse AED/ET effect), becomes insensitive to $I_{\text {rad }}$ at moderate $I_{\text {rad, }}$ and then correlates negatively with $I_{\text {rad }}$ at high $I_{\text {rad }}$ (due to the AED/ET predominating over PNS).

As $I_{\text {rad }}$ increases, IRR yield increases whereas its sensitivity to $I_{\text {rad }}$ decreases (hyperbolic response), mimicking the PNS response. Under light-saturation, IRR yield (like PNS) is insensitive to changes in $I_{\text {rad }}$, hence a given change in $I_{\text {rad }}$ estimations (via substituting $I_{\text {rad,meas }}$ with $I_{\text {rad,pred }}$ to drive GOSSYM) will translate to relatively little change in IRR yield estimations. As $I_{\text {rad }}$ decreases toward light-limitation, IRR yield (like PNS) becomes more sensitive to changes in $I_{\text {rad, }}$ and hence (depending on yield sensitivity to changes in PNS relative to changes in ET and in light-independent processes) IRR yield estimations become more sensitive to changes in $I_{\text {rad }}$ estimations. The RF yield response to changes in $I_{\text {rad }}$ depends on its sensitivity not only to changes in PNS and light-independent processes, but also to changes in ET.

Yield response to changes in $I_{\text {rad }}$ depends on limiting factors (environmental stresses, such as drought, temperature, and nutrients) governing yield. Interaction effects exist among various environmental parameters, such that yield response to changes in one parameter (e.g. $I_{\text {rad }}$ depends on the levels of other parameters (e.g. $\left.T_{\text {avg }}, P P T\right)$. Drought stress is greater under RF than under IRR conditions, particularly for droughtprone regions such as the arid Southwest. Differences between RF and IRR yields reflect drought stress effects. As observed in the regression results (Table 5a), yield estimation response to changes in $I_{\text {rad }}$ estimations is different between RF and IRR conditions, due to drought stress differences and interactions among various parameters affecting yield. The difference in yield estimation response (to changes in $I_{\text {rad }}$ estimations) between RF and IRR conditions depends on drought stress, which exhibits geographical (and associated regional climatic) variability. As drought stress increases, the difference between the $\mathrm{RF}$ and IRR yield estimation responses increases.

In summary, among the 4 TASs, 7 SRMs, 10 locations, and 2 management practices (RF and IRR), yield 
estimation accuracy depended on $I_{\text {rad }}$ estimation accuracy as well as on yield response (sensitivity) to changes in $I_{\text {rad, }}$ the latter of which depends on the following factors:

(1) Other parameters (i.e. weather, management, cultivar) besides $I_{\text {rad }}$ affect yield.

(2) Light-independent (as well as light-dependent) processes affect yield, whose overall response to changes in $I_{\text {rad }}$ depends on its relative responses to these 2 types of processes.

(3) Among light-dependent processes, yield response to changes in $I_{\text {rad }}$ depends on $I_{\text {rad }}$ level (i.e. lightlimitation versus light-saturation) and management practice (i.e. RF versus IRR); and on the sensitivity of light-dependent processes to changes in $I_{\text {rad }}$.

(4) Interaction effects among various parameters and the presence/magnitude of limiting factors (environmental stresses) affect yield response to changes in a given parameter (e.g. $\left.I_{\mathrm{rad}}\right)$.

3.3.2. Comparison of rainfed and irrigated yields, solar radiation models, and locations. Relative accuracies between RF and IRR yield estimations depended predominantly on location, and less so on SRM and TAS. RF yield was predicted more accurately than IRR yield at some locations, whereas vice versa was true for other locations. For the TmRnWn model-Scheme 1 scenario, IRR yield $\left(\mathrm{r}^{2}=0.843\right)$ was predicted more accurately than RF yield $\left(\mathrm{r}^{2}=0.632\right)$ at Stoneville, whereas $\mathrm{RF}$ yield $\left(\mathrm{r}^{2}=0.925\right)$ was predicted more accurately than IRR yield $\left(\mathrm{r}^{2}=0.321\right)$ at Meridianville (data not shown). For most of the 28 scenarios, RF yield was predicted more accurately than IRR yield at Meridianville, Florence, Lubbock, Artesia, Maricopa, and Springfield, whereas IRR yield was predicted more accurately than RF yield at Stoneville, Shafter, Corpus Christi, and Portageville.

For a given SRM and TAS, geographical composite estimations were more accurate (higher $\mathrm{r}^{2}$ ) for RF yields than for IRR yields (Table 5a). For example, for the TmRnWn-Scheme 1 scenario, geographical composite $\mathrm{r}^{2}$ was 0.933 and 0.827 for RF and IRR yields, respectively (Table 5a). Yield estimation accuracies were higher than $I_{\text {rad }}$ estimation accuracies; and effects of propagation of $I_{\text {rad }}$ estimation accuracies to generate yield estimations via GOSSYM depend on factors governing yield response to changes in $I_{\text {rad }}$. One of these factors, enumerated earlier, is interaction among environmental parameters and the influence of environmental stresses. Yield response to changes in $I_{\text {rad }}$ (hence yield estimation accuracy in response to changes in $I_{\text {rad }}$ estimations) is different between waterlimited (RF) and water-sufficient (IRR) conditions. Stress reduces yield and its response to changes in other parameters, resulting in lower yield variability. For a given change in $I_{\text {rad, }}$ RF yield changes by a smaller amount than IRR yield; and variability is lower for RF yield than for IRR yield. Decreased variability in yield facilitates higher yield estimation accuracy, just as decreased variability in daily weather parameters facilitates higher $I_{\text {rad }}$ estimation accuracy. Thus, decreased variability in RF yield relative to IRR yield (due to drought stress) results in increased estimation accuracies for RF yield compared to IRR yield, on average across geography, as shown by generally higher geographical composite $r^{2}$ for RF yield than for IRR yield (Table 5a).

For a given TAS and location, all 7 SRMs performed comparably well in predicting both RF and IRR yields, as shown by relatively narrow ranges of $\mathrm{r}^{2}$ (Table $5 \mathrm{a}$ ). Relative performances of the 7 SRMs depended on management strategy and location. For most of the 28 scenarios, the geographical composite $\mathrm{r}^{2}$ exceeded 0.80 for RF yield, IRR yield, and RF + IRR yield. For a given model, geographical composite $\mathrm{r}^{2}$ for RF, IRR, and RF + IRR yields showed little differences among the 4 TASs. Temporal averaging, while improving $I_{\text {rad }}$ estimation accuracy (Table 3 ), had a relatively negligible effect on yield estimation accuracy (Table 5a), probably because of the relative importance of other parameters and processes (besides $I_{\text {rad }}$ ) affecting yield, as well as $I_{\text {rad }}$ level and/or limiting factors (environmental stresses), as discussed in Section 3.3.1.

For a given SRM and TAS, RF + IRR yield estimations were most accurate (highest $\mathrm{r}^{2}$ ) for Shafter, followed by Maricopa (data not shown). These 2 locations also showed the highest $I_{\text {rad }}$ estimation accuracies among the 10 locations. For all 28 scenarios, $\mathrm{r}^{2}$ for RF + IRR yield for these 2 locations were consistently on the order of 0.99 or higher, and were relatively insensitive to SRM and TAS. As mentioned earlier, these 2 arid locations (Shafter and Maricopa) exhibit high air temperatures, low precipitation, and a large annual number of sunny days. The resultant highly predictable weather as affected by climate and geography produced superiorly accurate $I_{\text {rad }}$ estimations compared to other locations (Table 3), which were propagated to GOSSYM to generate similarly superior accuracies in yield estimations (Table 5a).

3.3.3. Best yield estimations. Comparing the 10 locations, 7 SRMs, and 4 TASs, best performances in predicting RF + IRR yield were obtained in Shafter and Maricopa, where all 28 scenarios performed comparably well and were reasonably accurate in predicting RF + IRR yields, as shown by $\mathrm{r}^{2}$ values on the order of 0.99 or higher. Geographical composite $r^{2}$ values for the 28 scenarios, with an indication of the best and worst SRM in predicting RF and IRR yields for each of the 4 TASs, are given in Table 4 . The combination of an accurate, reliable SRM, a double TAS to smooth out short-term temporal fluctuations in $I_{\text {rad }}$ (Scheme 4), 
and an arid location with highly predictable weather (Maricopa) contributed to high $I_{\text {rad }}$ estimation accuracy, which was propagated to GOSSYM to generate similarly high RF + IRR yield estimation accuracy.

\section{CONCLUSIONS}

A total of 28 scenarios $(7$ SRMs $\times 4$ TASs $)$ were assessed for $I_{\text {rad }}$ and RF/IRR cotton yield estimation accuracies at 10 U.S. locations and the geographical composite. The SRMs showed positive correlations of $I_{\text {rad }}$ with daylength and temperature range $\left(T_{\max }-\right.$ $\left.T_{\min }\right)$, and were reasonably accurate in predicting $I_{\mathrm{rad}}$ and yield. The SRM $I_{\text {rad }}$ estimation accuracy depended on TAS and location, whereas yield estimation accuracy depended more strongly on location and management practice than on TAS. The TmRnWn model performed best in predicting $I_{\text {rad, }}$, whereas all 7 SRMs performed comparably well in predicting yield.

$I_{\text {rad }}$ estimation accuracy depended on SRM, TAS, and location. High $\mathrm{r}^{2}$ and low MSD for Scheme 4, low $\mathrm{r}^{2}$ and high MSD for Scheme 1, and intermediate $\mathrm{r}^{2}$ and MSD for Schemes 2 and 3 for a given SRM and location show effects of temporal averaging in smoothing out short-term fluctuations and reducing temporal variability in $I_{\text {rad }}$. The TmRnWn model performed best for all 4 TASs for the geographical composite and the highest $I_{\text {rad }}$ estimation accuracies were obtained in Shafter and Maricopa. High $I_{\text {rad }}$ estimation accuracies at these 2 arid locations are due to their highly predictable weather. Such high predictability as affected by climate and geography renders $I_{\text {rad }}$ estimations relatively more accurate for a given SRM and TAS. Lower geographical composite $\mathrm{r}^{2}$ relative to location-specific $\mathrm{r}^{2}$ reflect geographical variability in $I_{\text {rad, }}$ which in turn illustrates effects of geography and associated changes in regional climate on measured $I_{\text {rad }}$ and on $I_{\text {rad }}$ estimation accuracy. The highest $I_{\text {rad }}$ estimation accuracy was obtained with the TmRnWn-Scheme 4 scenario in Maricopa $\left(r^{2}=0.999\right)$. For the geographical composite, the TmRnWn-Scheme 4 scenario was most accurate $\left(\mathrm{r}^{2}=0.994\right)$; and among the 7 SRMs, the TmRnWn model was most accurate for all 4 TASs. Due to error propagation, yield estimation accuracy depended on $I_{\text {rad }}$ estimation accuracy, as well as on yield response to changes in $I_{\text {rad }}$ as parameterized in GOSSYM.

Yield estimation accuracy depended on location and management practice (RF, IRR) and was relatively insensitive to SRM and TAS. Estimation accuracies were generally higher for yield than for $I_{\text {rad }}$. Temporal averaging improved $I_{\text {rad }}$ estimation accuracy but negligibly affected yield estimation accuracy, decreasing the estimation accuracy difference between yield and $I_{\text {rad }}$. Sources of variation between estimations and measurements were in the order LCS $>$ SDSD $>$ SB for $I_{\text {rad, }}$ and LCS $>$ SB $>$ SDSD for the RF and IRR yields, with LCS being the predominant contribution.

Yield estimation accuracy depended on $I_{\text {rad }}$ estimation accuracy and on yield response to changes in $I_{\mathrm{rad}}$, which depends on several factors. Various other parameters (i.e. weather, management, cultivar) besides $I_{\text {rad }}$ affect yield. Several light-independent (as well as light-dependent) processes also affect yield, whose response to changes in $I_{\text {rad }}$ depends on its response to these 2 types of processes. Among light-dependent processes, process sensitivity to changes in $I_{\text {rad }}$ depends on $I_{\text {rad }}$ level; and yield response to changes in $I_{\text {rad }}$ depends on the sensitivity of light-dependent processes to changes in $I_{\text {rad }}$. Interaction effects among various parameters and the presence of limiting factors (environmental stresses) affect yield response to changes in a given parameter.

All 7 SRMs performed comparably well in predicting both RF and IRR yields, with relative performances depending on management practice and location. The $\mathrm{RF}+\mathrm{IRR}$ yield estimations were most accurate for Shafter, followed by Maricopa. These 2 locations also showed the highest accuracies in $I_{\text {rad }}$ estimations. At these 2 locations, all 28 scenarios performed comparably well and were reasonably accurate in predicting RF + IRR yields.

Results of this research provide information on the performance of 7 SRMs and 4 TASs in predicting $I_{\text {rad }}$ and cotton yield. Coupled with CSMs, SRMs are useful in predicting both $I_{\text {rad }}$ and crop yield, particularly in regions where measured $I_{\text {rad }}$ data are not available. Future studies should examine the feasibility of incorporating these and other SRMs into various CSMs (in addition to GOSSYM) to predict yields of other crops (in addition to cotton).

Acknowledgements. Part of this research was funded by the National Aeronautical and Space Administration-funded Remote Sensing Technology Center at Mississippi State University. The authors thank Drs. Michael E. Brown, V. G. Kakani and Charles L. Wax for their comments regarding this manuscript. This is a contribution from the Department of Plant and Soil Sciences, Mississippi State University, Mississippi Agricultural and Forestry Experiment Station, Paper No. 10429.

\section{LITERATURE CITED}

Allen R (1995) Evaluation of procedures of estimating mean monthly solar radiation from air temperature. FAO, Rome

Allen R (1997) Self-calibrating method for estimating solar radiation from air temperature. J Hydrol Eng 2:56-67

Angstrom A (1924) Solar and terrestrial radiation. QJR Meteorol Soc 50:121-125

Baker DN, Lambert JR, McKinion JM (1983) GOSSYM: a simulator of cotton growth and yield. South Carolina Agric Expt Stn Tech Bull no 1089, Florence, SC 
Bennett I (1962) A method of preparing maps of mean daily global radiation. Arch Meteorol Geophys Bioklimatol Ser B 13:216-248

Bristow K, Campbell G (1984) On the relationship between incoming solar radiation and daily maximum and minimum temperature. Agric For Meteorol 31:159-166

Castillo H, Santibanez F (1981) Evaluacion de la radiacion solar global y luminosidad en Chile I. Calibracion de formulas para estimar radiacion solar global diaria. Agric Tec 41:145-152

Davies JA (1965) Estimation of insolation for West Africa. QJR Meteorol Soc 91:359-363

DeJong R, Stewart DW (1993) Estimating global solar radiation from common meteorological observations in western Canada. Can J Plant Sci 73:509-518

Doorenbos J, Pruitt W (1975) Crop water requirements. Irrigation and drainage paper, 24, FAO, Rome

Goldberg B, Klein WH, McCartney WD (1979) A comparison of some simple models used to predict solar irradiance on a horizontal surface. Sol Energy 23:81-83

Goodin DG, Hutchinson JMS, Vanderlip RL, Knapp MC (1999) Estimating solar irradiance for crop modeling using daily air temperature data. Agron J 91:845-851

Hargreaves GL, Hargreaves GH, Riley JP (1985) Irrigation water requirement for Senegal River Basin. J Irrig Drain Eng, ASCE 111:265-275

Hodges HF, Whisler FD, Bridges SM, Reddy KR, McKinion JM (1998) Simulation in crop management: GOSSYM/ COMAX. In: Peart RM, Curry RB (eds) Agricultural systems modeling and simulation. Marcel Dekker, New York, p 235-282

Hooke JE, McClendon RW (1992) Estimation of solar radiation data missing from long-term meteorological records. Agron J 84:739-742

Hunt LA, Kuchar L, Swanton CJ (1998) Estimation of solar radiation for use in crop modeling. Agric For Meteorol 91: 293-300

IPCC (Intergovernmental Panel on Climate Change) (2001) Climate change 2001: the scientific basis, 2001. Cambridge University Press, Cambridge

Kobayashi K, Salam MU (2000) Comparing simulated and measured values using mean squared deviation and its

Editorial responsibility: Robert Davis,

Charlottesville, Virginia, USA components. Agron J 92:345-352

Liu BYH, Jordan RC (1963) A rational procedure for predicting the long term average performance of flat-plate solar energy collectors. Sol Energy 7:53-74

Liu DL, Scott BJ (2001) Estimation of solar radiation in Australia from rainfall and temperature observations. Agric For Meteorol 106:41-59

Mahmood R, Hubbard KG (2002) Effect of time of temperature observation and solar radiation estimation for Northern Great Plains, USA. Agron J 94:723-733

Martinez-Lozano J, Tena F, Onrubia J, De la Rubia J (1984) The historical evolution of Angstrom formula and its modifications: review and bibliography. Agric For Meteorol 33:109-128

McCaskill MR (1990a) An efficient method for generation of full climatological records from daily rainfall. Aust J Agric Res 41:595-602

McCaskill MR (1990b) Estimation of solar radiation from rainday information using regionally stable coefficients. Aust J Agric Res 51:247-255

Meza F, Varas E (2000) Estimation of mean monthly solar global radiation as a function of temperature. Agric For Met 100:231-241

Monteith JL (1966) Local differences in the attenuation of solar radiation over Britain. QJR Meteorol Soc 92: $254-262$

Penman HL (1948) Natural evaporation from open water, bare soil and grass. Proc R Soc Lond Ser A 193:120-145

Reddy KR, Boone ML (2002) Modeling and validating cotton leaf area development and stem elongation. In: Leith $\mathrm{JH}_{\text {, }}$ Oki LR (eds) Proc 4th Int Symp on Crop Models. Acta Hort 593:193-199

Reddy KR, Hodges KF, McKinion JM (1997) Crop modeling and applications: a cotton example. In: Sparks DL (ed) Advances in agronomy, Vol 59. Academic Press, San Diego, CA, p 255-290

Reddy SJ (1971) An empirical method for estimating total solar radiation. Sol Energy 13:289-290

Richardson CW (1985) Weather simulation for crop management models. Trans Am Soc Agric Eng 28:1602-1606

Turc L (1961) Evaluation des besoins en eau d'irrigation. Evapotranspiration potentielle. Ann Agron 12:13-49

Submitted: November 3, 2003; Accepted: August 21, 2004 Proofs received from author(s): September 27, 2004 